

\title{
Are U.S. Commercial Banks Too Big?
}

\author{
Diego A. Restrepo ${ }^{1}$ \\ Department of Economics, State University of New York at Binghamton, New York, USA \\ EAFIT University, Medellín, Colombia. \\ Subal C. Kumbhakar \\ Department of Economics, State University of New York at Binghamton, New York, USA. \\ Kai Sun ${ }^{2}$ \\ Aston Business School, Aston University, UK.
}

\begin{abstract}
This paper presents new nonparametric measures of scale economies and TFP growth for U.S. banks. Unlike previous studies that use fully nonparametric models, our approach controls for time-invariant unobserved heterogeneity among banks in estimating returns to scale, TFP growth and its components. Using data for U.S. commercial banks from 2001 to 2010, we find evidence of significant scale economies across the entire bank size distribution. Returns to scale are persistent over time, decrease with bank size, and contribute significantly to TFP growth. Our results indicate that almost all small and medium size banks and most of the largest banks have strong economic incentives to keep growing. Thus, the consolidation of the banking industry is unlikely to retrench in the near future.
\end{abstract}

Keywords:

Banks, TFP growth, returns to scale, scale economies, nonparametric

JEL classification: D24, G21, C14

Email addresses: drestre1@binghamton. edu (Diego A. Restrepo ), kkar@binghamton. edu . (Subal C. Kumbhakar), k.sun@aston.ac.uk (Kai Sun )

${ }^{1}$ Restrepo acknowledges financial support from the Colombian Fulbright Commission, the Colombian Administrative Department of Science, Technology and Innovation (Colciencias), and EAFIT University.

${ }^{2}$ Corresponding author. 


\section{Introduction}

Bank size became a contentious issue after the recent U.S. financial crisis. The government bailout of some of the biggest U.S. banks angered the public, policy makers, and academics. However, proposals to break up these banks into smaller institutions failed to materialize, in part, because there is no consensus on the desirability or feasibility of capping the size of banks (Stern and Feldman 2009). More recently, however, the discussion has been reignited and capping the size of banks is again at the center of the policy debate. ${ }^{3}$ In this paper, we present evidence indicating that the behemoth size of some U.S. commercial banks seems quite normal and may still be below optimal. Thus, without regulatory intervention further bank growth and industry consolidation are unlikely to retrench.

Bankers, policy makers, and academics usually identify economies of scale as the main factor behind the ever increasing size of banks in the U.S. Bigger banks seems to benefit from spreading their investments over more output, save from consolidating operations, have access to a broader funding mix, diversify their assets over an expanded output mix, and, probably, increase their market power and political influence. However, the empirical evidence is inconclusive regarding the existence of economies of scale (RTS) for the biggest banks. In particular, RTS estimates differ substantially across studies depending on the methodology used in econometric estimation and/or the sample period under study.

Some studies find increasing RTS for small banks and constant or slightly decreasing RTS for large banks (e.g., Berger, Hanweck, and Humphrey 1987, Hunter and Timme 1991, Mester 1994, Clark 1996, Hughes and Mester 1998, and Wheelock and Wilson 2001). Other studies find increasing RTS even for the biggest financial institutions (e.g., Shaffer 1994, Berger and Mester 1997, Hughes and Mester 1998, Hughes, Mester, and Moon 2001, and Feng and Serletis 2010). In most recent works, Wheelock and Wilson $(2011,2012)$ present evidence indicating that all U.S. commercial banks, bank holding companies, and credit unions operate under increasing RTS. However, Feng and Zhang (2012) find decreasing RTS for large U.S. commercial banks. Thus, the existence of RTS for the biggest U.S. banks is still a matter of debate.

In this paper, we present new evidence suggesting that the majority of the biggest U.S. commercial banks still enjoy scale economies. Thus, they are not yet too big too exhaust the benefits from being big to reach their optimal scale size. ${ }^{4}$ However, we also find that some of the biggest

\footnotetext{
${ }^{3}$ See Johnson (2012) and the references therein.

${ }^{4}$ We find that estimates of RTS presented in some of the recent papers in the literature may be biased upward.
} 
banks exhibit constant or decreasing RTS, indicating that some of them have already attained their optimal scale size while some others are operating beyond their optimal size. In addition, we find that RTS contribute positively and significantly to TFP growth followed by allocative efficiency and technical change. TFP growth trends for big, medium, and small banks are similar. However, big banks experience sharper swings in TFP growth than medium and small banks.

Like Wheelock and Wilson, we avoid the problem of specifying a priori any functional form for the underlying cost function. However, unlike Wheelock and Wilson, our method exploits the dynamics between total cost and its determinants over time. We start from a nonparametric specification of the cost function of banks and then derive a growth equation for costs whose coefficients are nonparametric functions of the arguments of the cost function, viz., outputs, input prices, and other environmental/control variables. More specifically, we use the semiparametric smooth coefficient (SPSC) model of Kumbhakar and Sun (2012), Li, Huang, Li, and Fu (2002), and $\mathrm{Li}$ and Racine (2010) to estimate the functional coefficients. In our case the SPSC model arises naturally from the cost function framework and is not imposed a priori. We show that the functional coefficients of the SPSC model are nonparametric functions of the covariates of the cost function. Furthermore, these are uniquely related to TFP growth and its components, including RTS. Finally, to elucidate the estimates from the SPSC model, we also present results obtained from two parametric models derived within the same framework.

We find that most U.S. commercial banks still have economic incentives to keep growing. ${ }^{5}$ Our nonparametric RTS estimates indicate presence of economically and statistically significant scale economies for $98 \%$ of small and medium size banks, $73 \%$ of big banks, and $65 \%$ of the biggest one hundred banks. Median nonparametric RTS estimates are around 1.375. A bank with a RTS of 1.375 , for instance, could increase outputs by $10 \%$ by increasing costs by only $7.27 \%$ approximately $(1 / 1.375 \times 10 \%)$. Median RTS for small, medium, and big banks are 1.51, 1.31, and 1.14, respectively. For the biggest one hundred banks, median RTS is around 1.08. Thus, a $10 \%$ increase in all outputs will raise total cost by approximately $6.6 \%, 7.6 \%$, and $8.7 \%$ for small, medium, and big banks; and by $9.2 \%$ for the biggest one hundred banks.

Our estimates show that RTS decrease monotonically across bank size deciles: small banks exhibit higher scale economies followed by medium and big banks. The relation between mean

\footnotetext{
${ }^{5}$ We classify big banks as those with assets above $\$ 1$ billion dollars; medium banks as those with assets greater than $\$ 100$ million and lower than \$1 billion dollars; and small banks as those with assets below \$100 million dollars. For each year, we also rank banks by assets an select the top 100 biggest banks. As December 31, 2010; there were 479 big banks; 3,637 medium banks; and 2,290 small banks operating in the U.S. By comparison, as of December 31, 2000, there were 285 big banks; 2,397 medium banks; and 5,452 small banks.
} 
scale economies estimates and bank size is L-shaped across bank size deciles; indicating that after certain threshold, increases in bank size reduce scale economies only slightly or that RTS estimates are unrelated to bank size as measured by total assets. Thus scale economies seems to account only partially for the economic incentives for the growth of the biggest banks.

We also find that RTS estimates are persistent over time and influence positively and significantly to TFP growth. The median estimate of TFP growth per year was $2.4 \%$ which is mostly driven by scale and allocative components. Therefore, if banks care about achieving higher productivity levels, the consolidation of the banking industry is likely to continue driven by scale related gains.

The approach in this paper differs from earlier nonparametric studies (e.g., Wheelock and Wilson 2001, 2011, 2012) in some important ways. First, our model gives fully nonparametric estimates of TFP growth and its components, including RTS, and allows for the estimation of other important features of the underlying technology (e.g., output-cost elasticities, technical change (TC) and input price-cost elasticities). This, in turn, allows us to check the consistency of the results with theoretical restrictions-which is not done in others nonparametric studies. Second, we compute RTS for each bank-year observation instead of proxies for RTS. Third, unlike all previous papers, we estimate TFP growth components, including RTS, controlling for unobserved heterogeneity across banks—-failure to do so may lead to underestimation of RTS. ${ }^{6}$

We focus on the post-deregulation period of the U.S. banking industry to isolate RTS estimates from previous regulatory restrictions that may have blocked banks ability to grow to exploit scale economies. Our sample covers 60,868 bank-year observations for 7,473 commercial banks from 2001 to 2010. Unlike Wheelock and Wilson (2012), we exclude Bank Holding Companies which, given their idiosyncrasies, may not be adequately comparable with most commercial banks. Also, though quarterly data are available, we do not believe that each quarterly observation reflects banks' economic behavior at each point in time. Hence, we take quarterly averages to compute yearly observations. In line with Wheelock and Wilson, our approach incorporates a large sample of banks, a nonparametric specification of the cost function, fully flexible interactions among the explanatory variables, and includes off-balance sheet activities and equity capital as additional control variables.

\footnotetext{
${ }^{6}$ Ignoring unobserved heterogeneity leads to the "incidental parameters problem"; which, in turn, introduces biases and inconsistency in the estimation (See Mester 1997, Greene 2005a, Greene 2005b, Kumbhakar, Lien, Flaten, and Tveterås 2008, and Wang and Ho 2010). We also control for output quality, risk, and nontraditional activities to help capturing heterogeneity across banks that may be confounded with differing relative costs (e.g. Mester 1996, Rogers 1998) or masquerade endogenous sources of risk (e.g. Hughes and Mester 1998).
} 
To check the effects of modelling unobserved heterogeneity on our results, we also estimate RTS from a parametric model that does not control for such heterogeneity. Our findings indicate that failing to control for unobserved heterogeneity across banks may conceal evidence of increasing RTS. Using this model, we find scant evidence of scale economies: only small banks exhibit increasing RTS and most medium and large banks show either constant or decreasing RTS.

The rest of the paper is organized as follows. In Section 2, we review the literature. In Section 3, we describe our model, the estimation strategy, and our data. In Section 4, we present our empirical results; which we discuss in Section 5. Policy implications of our study is discussed in Section 6. Finally Section 7 concludes.

\section{Literature Review}

Firms differ substantially in their productivity levels even within narrowly defined industries. ${ }^{7}$ In the banking literature, researchers investigate such differences by examining TFP growth components, viz., efficiency and scale economies. Since surveys on bank efficiency are available elsewhere (e.g., Berger and Mester 1997), we focus only on the recent literature on scale economies.

During the early stages of deregulation of the U.S. banking industry, policy makers were concerned that a handful of big diversified banks could emerge and dominate the industry. Banks appeared to be able to profit from being bigger, threatening the viability of smaller specialized banks (Clark 1988). More recently, empirical evidence shows that advances in technology and changes in regulation favor large depository institutions (Wheelock and Wilson 2011). Economists think that economies of scale may explain such phenomena. However, the empirical evidence seems, at best, inconclusive.

Before 1970, empirical studies showed evidence of scale economies among commercial banks of all sizes (see Shaffer 1994 and the references therein). During the 1970's and 1980's, in contrast, the bulk of empirical evidence showed scale economies for only small depository institutions. ${ }^{8}$ For the 1990's, the evidence was mixed: some studies find evidence of scale economies for small banks only; ${ }^{9}$ while others present evidence of scale economies even for the largest banks. ${ }^{10}$ More recent

\footnotetext{
${ }^{7}$ Such differences stem from supply and demand-side factors. Supply-side factors include managerial ability, technological progress, scale economies, human capital, investment, R\&D, industry structure, ownership, and regulation. Demand-side factors include product substitutability, transportation costs, search costs, firm-customer's long-term relations, among others. See Bartelsman and Doms (2000) and Syverson (2011) for reviews of the literature.

${ }^{8}$ See Clark (1988), Berger et al. (1987), and Shaffer (1994).

${ }^{9}$ See Berger and Humphrey (1994), Berger et al. (1987), Hunter and Timme (1991), Mester (1994), Clark (1996), Hughes and Mester (1998), and Wheelock and Wilson (2001).

${ }^{10}$ See Shaffer (1994), Hughes, Lang, Mester, and Moon (1996, 2000), Berger and Mester (1997), Hughes and Mester (1998), Berger, Demsetz, and Strahan (1999), and Hughes et al. (2001).
} 
studies, with the exception of Feng and Zhang (2012), show evidence of scale economies across the entire bank size distribution. ${ }^{11}$

Wheelock and Wilson $(2011,2012)$ investigate scale economies of U.S. credit unions, commercial banks, and bank holding companies (BHC). Despite the continuous growth of these institutions since the 1980's, Wheelock and Wilson uncovered substantial economies of scale even for the largest institutions. Instead of using output-cost elasticities to measure economies of scale, as it is widely done in the literature, Wheelock and Wilson infer them using ray scale economies (RSE) and expansion-path scale economies (EPSE) indexes. ${ }^{12}$ They justify their choice arguing that using elasticities requires estimating derivatives of nonparametric functions which are noisier than estimates of the functions themselves. The drawback of this method is that RSE and EPSE estimates give only an indication of RTS rather than a measure of their magnitude. Also, from the econometric viewpoint, their estimation strategy involves a reduction of data dimensionality that can lead to noisier estimates.

Using yearly data from 1989-2006, Wheelock and Wilson (2011) find that all U.S. credit unions operate under increasing RTS and conclude that further consolidation of the industry and increasing average size are likely. Regarding commercial banks and bank holding companies, Wheelock and Wilson (2012) find similar results. Using quarterly data from 1984-2006, they find that RSE measures indicate increasing RTS for all banks in each period. Further, using EPSE measures they show that $99.7 \%$ of banks exhibit increasing RTS and the remaining banks experience constant RTS.

Wheelock and Wilson's results contrast with their earlier work, viz., Wheelock and Wilson (2001), in which they find that economies of scale were exhausted when banks have between $\$ 300$ and $\$ 500$ million of assets. They attribute their contrasting results to the use of a larger sample and a more realistic model of bank costs in which equity capital and off-balance sheet activities are explicitly incorporated.

Hughes and Mester (2011) also present evidence of increasing RTS for 842 U.S. large bank holding companies (BHC) operating during 2007. Unlike Wheelock and Wilson (2011, 2012), they use parametric methods in their estimations. Based on Hughes et al. (1996), Hughes and Mester (1998), Hughes et al. (2001), and Hughes and Mester (2010), they argue that studies usually failed

\footnotetext{
${ }^{11}$ These studies include Wheelock and Wilson (2011, 2012), Hughes and Mester (2011), Feng and Serletis (2010).

${ }^{12} \mathrm{RSE}$ are computed using the ratio of successive nonparametric local-linear estimates of the cost function along a ray passing through the observed output vector and $\theta \mathbf{y}_{\mathbf{0}}$ for $\theta \in[0.05,0.10, \ldots, 1,2, \ldots, 25]$. Similarly, EPSE are computed from successive nonparametric estimates of the cost function as one moves along the path $\theta(1-\gamma) \mathbf{y}$ to $\theta(1+\gamma) \mathbf{y}$ for small values of $\gamma$ and varying $\theta$.
} 
to uncover increasing RTS for large banks due to misspecification of the bank cost or profit model. For example, early studies using data from the 1980's did not consider managerial risk preferences and the endogenous risk taking behavior of banks. Large banks may have lower marginal costs in risk management due to diversification. This, in turn, may lead banks to take on more risk until all the scale-related cost savings are exhausted, reducing measured scale economies.

Hughes and Mester (2011) use four different model specifications. The first model omits equity capital as a conditioning variable and also omits the cost of equity in the cost function. Using this model, they find slightly increasing RTS for all BHC in the sample. Using a second model, in which equity capital enters as a conditioning variable, they find decreasing RTS for all BHC. Results from a third model incorporating the shadow cost of equity shows slightly increasing RTS for all BHC. However, the RTS estimates are statistically indistinguishable from those of the first model. Finally, using a fourth model incorporating managerial preferences and conditioning on the optimal level of equity capital, they find substantial scale economies for all BHC. In this case, RTS range from 1.13 for the smallest $\mathrm{BHC}$ to 1.35 for the largest $\mathrm{BHC}$. The estimated RTS, however, increase monotonically with BHC's size. This result is puzzling since most empirical evidence, including Wheelock and Wilson $(2011,2012)$, show that RTS monotonically decrease as bank size increases.

Feng and Serletis (2010) also present new evidence of increasing RTS for large banks. Unlike Wheelock and Wilson $(2011,2012)$ and Hughes and Mester (2011) who use a cost function, Feng and Serletis use a fully parametric output distance function which does not require data on factor prices. They use data for U.S. banks with assets in excess of \$1 billion from 2001 to 2005. The main contribution of their paper is methodological in nature. They impose monotonicity and curvature constraint on the underlying bank production technology using Bayesian techniques. They claim that without such constraints estimates of RTS and TFP growth are distorted. They obtain RTS estimates in the range from 1.037 to 1.056, indicating moderate increasing RTS for all banks in the sample. Nonetheless, from their paper, it is not clear if these results are entirely driven by their method, since they omit a comparison with the alleged misspecified model. Furthermore, in almost all banking studies, outputs are treated as exogenous and inputs endogenous. If this is the case, one should use an input distance function in which outputs and input ratios appearing as regressors are exogenous (Das and Kumbhakar 2012). The use of output distance function suffers from endogeneity problem when inputs are endogenous.

Taking together, these studies suggest that most banks operate under increasing RTS. However, 
Feng and Zhang (2012) find that large and small banks exhibit near constant RTS. As in Feng and Serletis, they use an output distance function to model banks' technology, use Bayesian techniques for estimation, and impose monotonicity and curvature conditions to the underlying technology. They include continuously operating large banks (assets above $\$ 1$ billion), large community banks (assets below $\$ 1$ billion and above $\$ 100$ million), and small community banks (assets below $\$ 100$ million) from 1997 to 2006. The main distinction with Feng and Serletis's work is that Feng and Zhang explicitly account for technical inefficiency and unobserved heterogeneity across banks in their estimation. Their results suggest that failing to do so leads to higher RTS estimates. In particular, without accounting for unobserved heterogeneity, large banks exhibit increasing RTS ranging from 1.022 in 1997 to 1.01 in 2006 . However, when unobserved heterogeneity is incorporated these results disappear: all large banks now exhibit constant RTS.

One important criticism that may be raised against Feng and Zhang's results is that they do not include any proxies for risk taking behavior as it is done in Hughes and Mester (2011) or Wheelock and Wilson $(2011,2012)$. Nonetheless, the fact that these latter studies do not account for unobserved heterogeneity across banks also may raise questions about their reliability in line with Feng and Zhang's claims. Thus, the literature will benefit from a further investigation on these issues using a methodology that may combine the insights of these three lines of research: i) controlling for unobserved heterogeneity across banks, ii) conditioning on bank risk taking behavior, and iii) using flexible functional specifications for the underlying technology. ${ }^{13}$ Our paper goes one step forward in this direction. ${ }^{14}$

Another way to rationalize the observed increasing size of banks is to look at the distribution of TFP components across different bank size categories. If TFP growth differs across the bank size distribution, some banks will have incentives to increase their scale of operations, even though, by itself, this strategy may have negligible or negative impact on their performance. For instance, Hunter and Timme $(1986,1991)$ investigate how technical change interacts with bank size and scale economies. Using data for U.S. bank holding companies from 1972 to 1982, they find that technical change is associated with increases in scale economies: technological change lowers cost by $1 \%$ per year, increases the cost-minimizing scale of operations, and affects banks' product mix.

Early studies indicate that TFP growth in the U.S. banking during the 1980's was modest or

\footnotetext{
${ }^{13}$ The international evidence also points toward the existence of scale economies only for small and medium-sized banks, Amel, Barnes, Panetta, and Salleo (2004). Allen and Liu (2007), on the other hand, report economies of scale for the six largest Canadian banks.

14 Restrepo and Kumbhakar (2011) using data for all U.S. commercial banks from 2001 to 2010 also document constant RTS for most U.S. banks from 2001-2010.
} 
slightly negative (Humphrey 1991, 1992, 1993, Bauer, Berger, and Humphrey 1993, Wheelock and Wilson 1999, Stiroh 2000, Semenick Alam 2001, Berger and Mester 2003, Daniels and Tirtiroglu 1998). Tirtiroglu, Daniels, and Tirtirogu (2005) investigate how the regulatory structure of the time might have contributed to this phenomenon. They find that deregulation had a positive impact on banks' long-run productivity growth, confirming the priors that the poor productivity growth was due to regulatory restrictions. More recently, however, Mukherjee, Ray, and Miller (2001) and Semenick Alam (2001) find positive productivity growth for large U.S. banks over roughly the same period, indicating that larger banks may have taken better advantage of technological progress and deregulation.

During the period 1997-2006, Feng and Zhang (2012) find positive productivity growth for large banks, $2.04 \%$ per year on average, but poor productivity growth for small banks, $0.3 \%$ per year on average. They also show that most productivity growth gains are due to technical change and not to efficiency gains. ${ }^{15}$ This results echo those of Feng and Serletis (2010) who show that technical change contributed to $70 \%$ of total productivity growth and scale economies only account for $7 \% .{ }^{16}$

\section{Methodology}

\subsection{The Model}

We use a nonparametric cost function with $Q$ outputs, $K$ inputs, and $P$ environmental variables to control for bank-specific characteristics. The cost function for bank $i$ at time $t$ has the following general specification:

$$
C_{i t}=A_{i t} \cdot B_{i} \cdot H\left(W_{i t}, Y_{i t}, t, Z_{i t}\right)
$$

where $C_{i t}$ represents actual cost, $A_{i t}$ is an productivity parameter, $B_{i}$ is a parameter capturing timeinvariant unobserved heterogeneity across banks (fixed-effects), $H(\cdot)$ is a nonparametric function of $W_{i t}$, a vector of input prices, $Y_{i t}$, a vector of output quantities, and $Z_{i t}$, a vector of control variables.

We impose homogeneity restrictions on input prices by dividing costs and input prices by the price of input $K$, i.e., $W_{K}$. Thus, the cost function becomes:

$$
\widetilde{C}_{i t}=A_{i t} \cdot B_{i} \cdot H\left(\widetilde{W}_{i t}, Y_{i t}, t, Z_{i t}\right)
$$

\footnotetext{
${ }^{15}$ The results for large banks are comparable to those in Feng and Serletis (2010)

16 See Hughes et al. (2001) and Hughes and Mester (2010) on the impact of using different models on estimates of TFP components (e.g. scale economies, efficiency, technical change, etc.).
} 
where $\widetilde{W}_{k}=W_{k} / W_{K}$ and $\widetilde{C}_{i t}=C / W_{K}$. Taking logarithm to (2) and denoting $\ln H(\cdot)=f(\cdot)$, we can write:

$$
\ln \widetilde{C}_{i t}=f\left(\widetilde{W}_{i t}, Y_{i t}, t, Z_{i t}\right)+\ln A_{i t}+\ln B_{i}
$$

Dropping the subscripts and taking the total derivative of (3), we get the following growth formulation:

$$
\frac{d \ln \widetilde{C}}{d t}=\frac{\partial f}{\partial t}+\sum_{k=1}^{K-1} \frac{\partial f}{\partial \ln \widetilde{W}_{k}} \cdot \frac{d \ln \widetilde{W}_{k}}{d t}+\sum_{q=1}^{Q} \frac{\partial f}{\partial \ln Y_{q}} \cdot \frac{d \ln Y_{q}}{d t}+\sum_{p=1}^{P} \frac{\partial f}{\partial Z_{p}} \cdot \frac{d Z_{p}}{d t}+\frac{\partial \ln A}{\partial t}
$$

We write (4) in a more compact way to get our estimating growth equation:

$$
\dot{\bar{C}}=\beta_{0}(\cdot)+\sum_{k=1}^{K-1} \beta_{k}(\cdot) \dot{\vec{W}}_{k}+\sum_{q=1}^{Q} \gamma_{q}(\cdot) \dot{Y}_{q}+\sum_{p=1}^{P} \varphi_{p}(\cdot) \nabla_{t} Z_{p}+u
$$

where, in generic terms, $\dot{X}=d \ln X / d t$ and $\nabla_{t} X=d X / d t$. We interpret $u=\partial \ln A / \partial t$ as an error term capturing productivity shocks and establish the following mapping for the functional coefficients:

$$
\beta_{0}(\cdot)=\frac{\partial f}{\partial t} ; \quad \beta_{k}(\cdot)=\frac{\partial f}{\partial \ln \widetilde{W}_{k}} ; \quad \gamma_{q}(\cdot)=\frac{\partial f}{\partial \ln Y_{q}} ; \quad \varphi_{p}(\cdot)=\frac{\partial f}{\partial Z_{p}}
$$

Note that the growth formulation of the cost function in (4) automatically controls for unobserved time-invariant heterogeneity across banks by removing the fixed-effects parameters. Finally, the functional coefficients have clear economic meaning. The estimated functional coefficients can be used to get estimates of TFP growth and its components as shown in the next subsection.

\subsection{Total Factor Productivity Change}

We start with the standard definition of TFP change (see Denny, Fuss, and Waverman 1979):

$$
T \dot{F} P \equiv \sum_{q=1}^{Q} R_{q} \dot{Y}_{q}-\sum_{k=1}^{K} S_{k} \dot{X}_{k}
$$

where $R_{q}$ denotes the revenue share of each output $(q=1, \ldots, Q)$ and $S_{k}$ the cost share of each input $(k=1, \ldots, K)$. 
Adding $T \dot{F} P$ to both sides of (5):

$$
T \dot{F} P+\beta_{0}(\cdot)+\sum_{k=1}^{K-1} \beta_{k}(\cdot) \dot{\tilde{W}}_{k}+\sum_{q=1}^{Q} \gamma_{q}(\cdot) \dot{Y}_{q}+\sum_{p=1}^{P} \varphi_{p}(\cdot) \nabla_{t} Z_{p}+u \equiv \dot{\widetilde{C}}+\sum_{q=1}^{Q} R_{q} \dot{Y}_{q}-\sum_{k=1}^{K} S_{k} \dot{X}_{k}
$$

Using the definitions $\dot{\widetilde{C}}=\dot{C}-\dot{W}_{K}$ and $\dot{C}=\sum_{k=1}^{K} S_{k} \dot{W}_{k}+\sum_{k=1}^{K} S_{k} \dot{X}_{k}$, the right-hand-side of (8) can be expressed as:

$$
\dot{\widetilde{C}}+\sum_{q=1}^{Q} R_{q} \dot{Y}_{q}-\sum_{k=1}^{K} S_{k} \dot{X}_{k} \equiv \sum_{k=1}^{K} S_{k} \dot{W}_{k}+\sum_{q=1}^{Q} R_{q} \dot{Y}_{q}-\dot{W}_{K}
$$

Since $\sum_{k=1}^{K} S_{k}=1, \dot{W}_{k}=\dot{\widetilde{W}}_{k}+\dot{W}_{K}, \forall k=1, \ldots, K-1$, and $\dot{W}_{K}=0$,

$$
\sum_{k=1}^{K} S_{k} \dot{W}_{k}+\sum_{q=1}^{Q} R_{q} \dot{Y}_{q}-\dot{W}_{K} \equiv \sum_{k=1}^{K-1} S_{k} \dot{\vec{W}}_{k}+\sum_{q=1}^{Q} R_{q} \dot{Y}_{q}
$$

Using this result, the relationship in (8) can be expressed as:

$$
T \dot{F} P \equiv-\beta_{0}(\cdot)+\sum_{q=1}^{Q}\left(R_{q}-\gamma_{q}(\cdot)\right) \dot{Y}_{q}+\sum_{k=1}^{K-1}\left(S_{k}-\beta_{k}(\cdot)\right) \dot{\tilde{W}}_{k}-\sum_{p=1}^{P} \varphi_{p}(\cdot) \nabla_{t} Z_{p}-u
$$

Therefore, the relationship in (11) decomposes TFP growth into five components. The first term is the technical change component $\left(T C=-\partial \hat{f} / \partial t=-\hat{\beta}_{0}(\cdot)\right)$ which captures shifts of the estimated cost function over time (percentage change in cost over time, ceteris paribus). $T C<0$ indicates technical progress (cost diminution). A positive value of TC will indicate technical regress. The second term $\left(S C=\sum_{q=1}^{Q}\left(R_{q}-\gamma_{q}(\cdot)\right) \dot{Y}_{q}\right)$ can be decomposed into two components by expressing it as $(R T S-1) \sum_{q=1}^{Q} \gamma_{q}(\cdot) \dot{Y}_{q}+\sum_{q=1}^{Q}\left(R_{q}-\gamma_{q}(\cdot) / \Gamma(\cdot)\right) \dot{Y}_{q}$ where $\Gamma(\cdot)=\sum_{q} \gamma_{q}(\cdot)$, and $R T S=(\Gamma(\cdot))^{-1}$. The first part of it clearly depends on RTS and the second part depends on mark-up (departure of output prices from their respective marginal costs). The third term $\left(A L=\sum_{k=1}^{K-1}\left(S_{k}-\beta_{k}(\cdot)\right) \dot{\vec{W}}_{k}\right)$ corresponds to the allocative component because it captures the effects of non-optimal input allocation (deviation of input mix from the optimal). The fourth term $\left(E X=-\sum_{p=1}^{P} \varphi_{p}(\cdot) \nabla_{t} Z_{p}\right)$ captures the effect of other factors such as output quality, risk, and other variables. Finally, the last term $(-u)$ is viewed as a productivity shock component which can increase/decrease TFP growth. We assume it to be random with mean zero, and can be measured residually. Note that the TFP growth components are nonparametric functions that can be computed after estimating (5). 


\subsection{Econometric Model}

We estimate the functional coefficients in (5) using three different models. First, note that $f(\cdot)$ in (5) can be thought of as an unknown smooth function of $t, \ln \widetilde{W}_{k}, \ln Y_{q}$, and $Z_{p}$, then its gradients, i.e., $\beta_{0}, \beta_{k}, \forall k=1, \ldots, K-1, \gamma_{q}, \forall q=1, \ldots, Q$, and $\varphi_{p}, \forall p=1, \ldots, P$, are also unknown smooth functions of these variables as shown in (6). As a result of these, (5) can be viewed as the SPSC model of Li et al. (2002) where the model is linear in the $\dot{\widetilde{W}}_{k}, \forall k=1, \ldots, K-1, \dot{Y}_{q}, \forall q=1, \ldots, Q$, and $\nabla_{t} Z_{p}, \forall p=1, \ldots, P$, variables. To simplify notation, we rewrite (5) (after adding the subscript $i$ and $t$ for observation in the cross-section and time dimension, respectively) as

$$
\mathcal{Y}_{i t}=\mathcal{X}_{i t}^{\prime} \Psi\left(\mathcal{Z}_{i t}\right)+u_{i t}
$$

where $\mathcal{Y}_{i t}=\dot{\widetilde{C}}_{i t} ; \mathcal{X}_{i t}^{\prime}=\left[1, \dot{\widetilde{W}}_{1 i t}, \ldots, \dot{\widetilde{W}}_{K-1 i t}, \dot{Y}_{1 i t}, \ldots, \dot{Y}_{Q i t}, \nabla_{t} Z_{1 i t}, \ldots, \nabla_{t} Z_{P i t}\right]$,

$\mathcal{Z}_{i t}^{\prime}=\left[\ln \widetilde{W}_{1 i t}, \ldots, \ln \widetilde{W}_{K-1 i t}, \ln Y_{1 i t}, \ldots, \ln Y_{Q i t}, t_{i t}, Z_{1 i t}, \ldots, Z_{P i t}\right]$;

$\Psi^{\prime}(\cdot)=\left[\beta_{0}(\cdot), \beta_{1}(\cdot), \ldots, \beta_{K-1}(\cdot), \gamma_{1}(\cdot), \ldots, \gamma_{Q}(\cdot), \varphi_{1}(\cdot), \ldots, \varphi_{P}(\cdot)\right]$. We call this model the semiparametric growth model (SPG model).

Following Li et al. (2002) and Li and Racine (2007), the local-constant estimator for $\Psi(z)$ is expressed as:

$$
\hat{\Psi}(z)=\left[\sum_{i=1}^{N} \sum_{t=1}^{T} \mathcal{X}_{i t} \mathcal{X}_{i t}^{\prime} \mathcal{K}\left(\frac{\mathcal{Z}_{i t}-z}{h}\right)\right]^{-1} \sum_{i=1}^{N} \sum_{t=1}^{T} \mathcal{X}_{i t} \mathcal{Y}_{i t} \mathcal{K}\left(\frac{\mathcal{Z}_{i t}-z}{h}\right)
$$

where $N$ and $T$ denotes number of banks and time periods, respectively, $h$ is a $(K+Q+P)$ vector with each element a selected bandwidth for each $z$ variable and $\mathcal{K}(\cdot)$ is the product Gaussian kernel function. ${ }^{17}$

Note that if the kernel function is eliminated, then the SPSC estimator reduces to its OLS counterpart. The SPSC model also nests the partially linear model proposed by Robinson (1988) as a special case, which makes only the intercept an unknown smooth function of $\mathcal{Z}$ variables.

Following Li and Racine (2010), we employ the most commonly used least-squares crossvalidation (LSCV) method, which is a fully automatic data-driven approach, to select the band-

\footnotetext{
${ }^{17}$ Explicitly, the kernel function is written as:

$$
\mathcal{K}(\cdot)=\prod_{l=1}^{K+Q+P} \frac{1}{\sqrt{2 \pi}} \exp \left(-\frac{1}{2}\left(\frac{\mathcal{Z}_{l i t}-z_{l}}{h_{l}}\right)^{2}\right)
$$
}


width vector $h$, i.e.,

$$
C V_{l c}(h)=\min _{h} \sum_{i=1}^{N} \sum_{t=1}^{T}\left[\mathcal{Y}_{i t}-\mathcal{X}_{i t}^{\prime} \hat{\Psi}_{-i t}\left(\mathcal{Z}_{i t}\right)\right]^{2} M\left(\mathcal{Z}_{i t}\right)
$$

where $C V_{l c}(h)$ determines the cross-validation bandwidth vector $h$ for local constant estimator, $\mathcal{X}_{i t}^{\prime} \hat{\Psi}_{-i t}\left(\mathcal{Z}_{i t}\right)=\mathcal{X}_{i t}^{\prime}\left[\sum_{j \neq i}^{N} \sum_{\tau \neq t}^{T} \mathcal{X}_{j \tau} \mathcal{X}_{j \tau}^{\prime} \mathcal{K}\left(\frac{\mathcal{Z}_{j \tau}-z_{i t}}{h}\right)\right]^{-1} \sum_{j \neq i}^{N} \sum_{\tau \neq t}^{T} \mathcal{X}_{j \tau} \mathcal{Y}_{j \tau} \mathcal{K}\left(\frac{\mathcal{Z}_{j \tau}-z_{i t}}{h}\right)$ is the leave-one-out local-constant kernel conditional mean, and $0 \leq M(\cdot) \leq 1$ is a weight function that serves to avoid difficulties caused by dividing by zero. The bandwidth for the $\mathcal{Z}$ variables and the smooth coefficients can be estimated using the NP package (Hayfield and Racine 2008) in R. ${ }^{18}$

Second, we estimate (5) assuming that the underlying technology can be represented by a translog cost function. In this case, the functional coefficients in (5) are parametric functions of $\left[W_{i t}, Y_{i t}, t, Z_{i t}\right]$ that can be estimated by OLS (equation (A.7) in Appendix A). We call this model the parametric growth model (PG model). ${ }^{19}$

Third, to make our results comparable to the previous literature, we estimate the cost function (1) instead of (5) assuming that the underlying technology can be represented by a translog cost function. However, unlike the PG model, equation (1) does not control for unobserved timeinvariant heterogeneity across banks, see Appendix A. After estimating the coefficients, we compute the functional coefficients in (5). We call this model the parametric log model (PL model).

The three models described above (SPG model, PG model, and PL model) differ in terms of their assumptions about the data generating process and the functional form of the underlying technology. Contrary to the PL model, both the SPG and PG models control for time-invariant unobserved heterogeneity across banks. Unlike the SPG model, the PG model assumes a parametric and common technology across banks. The functional coefficients of the SPG model are fully nonparametric while the PG and PL models' functional coefficients are parametric functions. In this sense the SPG model is the most general among the three.

\subsection{Data}

We use data from the Report of Conditions and Income (Call Reports) from the Federal Reserve Bank of Chicago. We include all FDIC insured commercial banks with available data between

\footnotetext{
${ }^{18}$ We use the functions npscoefbw and npscoef with their default values. To decrease the estimation computational time, we set the optimization options to "nmulti=1", "optim.abstol $=0.000001$ ", and "optim.reltol $=\operatorname{sqrt}(0.000001)$ ".

${ }^{19}$ Using both the SPG and PG models, we avoid the incidental parameter problem. Consistency of the functional coefficients follow from the standard SPSC model (Li et al. 2002) and the standard linear panel data models as the number of observations grow to infinity.
} 
2001Q1 and 2010Q4. We exclude banks reporting negative values for assets, equity, outputs and prices, stand alone internet banks, commercial banks conducting primarily credit card activities, and banks chartered outside continental U.S. territory. Our data set is an unbalanced panel with 63,120 bank-year observations for 8,483 banks. We deflate all nominal quantities using the 2005 Consumer Price Index for all urban consumption published by the Bureau of Labor Statistics.

Our method is computationally demanding. To avoid extreme outliers, we use data for which output quantities and input prices fall between $0.5 \%$ and the $99.5 \%$ of their empirical distributions. In addition, we only consider banks with at least four years of available data from 2001 to 2010. To get annual values, we compute the quarterly average of balance-sheet nominal (stock) values. As a result, we have 60,868 bank-year observations for 7,473 different banks. Our growth formulation further decreases the number of observation to 51,966 bank-year observations for 7,381 banks.

In this framework, a bank's balance-sheet captures the essential structure of banks' core business: (i) liabilities, together with physical capital and labor, are inputs into the bank production process and (ii) assets, other than physical assets, are outputs. Liabilities are composed of core deposits and purchased funds. Assets include loans and trading securities. Therefore, banks use labor, physical capital, and debt to produce loans, invest in financial assets, and facilitate other financial services.

We define five output variables: household and individual loans $\left(Y_{1}\right)$, real estate loans $\left(Y_{2}\right)$, business loans $\left(Y_{3}\right)$, securities (e.g., federal funds sold and securities purchased under agreements to resell) $\left(Y_{4}\right)$, and other assets $\left(Y_{5}\right)$. These outputs are essentially the same as those used in Berger and Mester (2003).

We define five input variables: labor (e.g., number of full-time equivalent employees at the end of each quarter) $\left(X_{1}\right)$, physical capital (e.g. premises and fixed assets including capitalized leases) $\left(X_{2}\right)$, purchased funds (e.g., federal funds purchased and securities sold under agreements to repurchase, total trading liabilities, other borrowed money, and subordinated notes and debentures.) $\left(X_{3}\right)$, interest-bearing transaction accounts $\left(X_{4}\right)$, and non-transaction accounts $\left(X_{5}\right)$. The price of each input, $W_{j}$ for $j=1, \ldots, 5$, is computed by dividing total expenses by the corresponding input quantity. Total costs, $C$, equals the sum of expenses on each of the five inputs; total revenues, equals the sum of revenues for each output category. Table 1 presents summary statistics for outputs, inputs, and input prices.

Table 1 also presents information on cost, revenue, and output shares. On the revenue side, real estate loans account for $41.6 \%$ of total banks' revenues $\left(R_{2}\right)$, loan to business and other insti- 
tutions $20.5 \%\left(R_{3}\right)$, securities $15.3 \%\left(R_{4}\right)$, and other assets $16.1 \%\left(R_{5}\right)$. Loans to individuals and households account for $6 \%\left(R_{1}\right)$ of total revenue. On the cost side, labor $41.3 \%$ of total costs $\left(S_{1}\right)$, non-transaction accounts expenditures represent $29.2 \%\left(S_{5}\right)$, premises and fixed assets $10.3 \%$ $\left(S_{2}\right)$, purchased funds $16.6 \%\left(S_{3}\right)$, and transaction accounts $2.6 \%\left(S_{4}\right)$. In addition, Table 1 also reports output shares for each output category, $S Y_{i}$; and the share of total loans on total output, $S Y_{123}$. As control variables, we use the log of total equity capital $\left(Z_{1}\right)$, we include a proxy for offbalance sheet activities $\left(Z_{2}\right.$ : noninterest income over total income), and a proxy for output quality $\left(Z_{3}\right.$ : non performing loans).

\section{Empirical Results}

Both the SPG model and the PG models fit the data quite well (the $R^{2}$ values for these models are $0.978,0.916){ }^{20}$ The PG model is a restricted version of the SPG model. Thus, we can test if the data support the parametric restrictions imposed by the PG model. Using the specification test of Li and Racine (2010), we reject the PG model in favor of the SPG model specification. ${ }^{21}$ Thus, on statistical grounds our preferred specification is the SPG model. However, our findings regarding RTS and TFP growth components from the SPG and PG models are quite similar. For completeness and comparability with the literature, we present parameters, RTS, and TFP growth components from all three models.

\subsection{Estimated Functional Coefficients}

In additional to allowing the core cost function to be nonparametric, the functional coefficients are also fully nonparametric and have clear economic meaning. As mentioned before $\beta_{0}(\cdot)$, the intercept of the SPSC model represents shift of the cost function (percentage change in cost, ceteris paribus). Similarly, the $\beta_{k}(\cdot)$ are cost elasticities of input prices which are cost shares. The $\gamma_{q}(\cdot)$ coefficients are cost elasticity of outputs which are uniquely related to RTS. Finally, the $\varphi_{p}(\cdot)$ coefficients measure the effects of environmental variables on percentage change in cost. We present summary statistics for the functional coefficients estimates in Table 2 and their empirical distributions in Figure 1.

It can be seen from Table 2 that mean TC is almost zero in SPG and PL models. However looking at the mean might give a misleading impression. A closer look at TC in the PL shows that

\footnotetext{
${ }^{20}$ The fit of the PL model $\left(R^{2}\right)$ is not comparable to the other two models because the dependent variables are not the same. The $R^{2}$ of the PL model is 0.847 .

${ }^{21}$ We use 99 bootstrap replications which gave a p-value of almost zero.
} 
it is almost zero for each percentile while for the SPG model there is technical progress (negative TC) for almost half of the banks while for the other half there is technical regress, resulting in a technical regress of $0.1 \%$ per annum. On the other hand, the PG model shows technical progress for more than $75 \%$ of the banks ranging from $2.1 \%$ to $0.00 \%$. On average, technical progress took place at the rate of $1 \%$ per annum.

By Shephard's lemma, the coefficients $\hat{\beta}_{k}(\cdot)=\partial \ln C / \partial \ln W_{k}$, are cost shares estimates for each input, $k=1,2,3,4$. The mean and the empirical distributions of $\hat{\beta}_{k}(\cdot)$ from the SPG and PG models are similar and closely follow the observed cost shares shown in Table 2. The estimates from the PL model follow a similar pattern but their empirical distributions differ significantly. Negative values for $\hat{\beta}_{k}(\cdot), k=1,2,3,4$., indicate violations of regularity conditions since cost shares are positive. The results show that most $\hat{\beta}_{k}(\cdot)$ are positive. For the SPG model the violations are less than $0.5 \%$ for $\hat{\beta}_{1}(\cdot)$ and $\hat{\beta}_{3}(\cdot)$, and around $6 \%$ for $\hat{\beta}_{2}(\cdot)$ and $\hat{\beta}_{4}(\cdot)$. For the PG model, the violations are less than $0.5 \%$ for all $\hat{\beta}_{k}(\cdot)$. The PL model has the greatest number of violations, $27 \%$ and $11.5 \%$ for $\hat{\beta}_{2}(\cdot)$ and $\hat{\beta}_{4}(\cdot)$, respectively. Our results imply that controlling for unobserved heterogeneity using the SPG or the PG models reduces the number of violations significantly.

Estimated cost elasticity with respect to each output is given by $\hat{\gamma}_{q}(\cdot)$. We expect these coefficients to have a positive sign since both marginal and average cost are positive. In fact, this is the case for most observations. Estimates of $\gamma_{q}(\cdot)$ from the PG model are negative for less than $0.8 \%$ of all observations. The SPG model shows negative values for $\hat{\gamma}_{2}(\cdot)$ to $\hat{\gamma}_{4}(\cdot)$ for less than $1.2 \%$ of the observations. The corresponding values for $\hat{\gamma}_{1}(\cdot)$ and $\hat{\gamma}_{5}(\cdot)$ are $5.6 \%$ and $6.25 \%$. Overall, the PL model have negative values for $\hat{\gamma}_{k}(\cdot)$ for less than $6 \%$ of the observations. The low number of violations for the SPG model is remarkable since its estimated coefficients are fully nonparametric functions. Better performance of the PG model in this regard suggests that the PG model is a good approximation of the underlying technology. We consider that the number of sign violations for the estimated coefficients $\hat{\beta}_{k}(\cdot)$ and $\hat{\gamma}_{k}(\cdot)$ using the SPG and PG models are low. Thus, we do not restrict their signs. ${ }^{22}$

The $\hat{\varphi}_{p}(\cdot)=\partial \hat{f} / \partial Z_{p}$ coefficients capture the effects of log of equity capital $\left(Z_{1}\right)$, off-balance sheet activities $\left(Z_{2}\right)$, and non-performing loans $\left(Z_{3}\right)$ on log total cost. More specifically, $\hat{\varphi}_{1}(\cdot)$ represents cost elasticity of equity capital, while $\hat{\varphi}_{p}(\cdot), p=2,3$ represents semi cost elasticity of off-balance sheet activities and non-performing loans. For the SPG and PG models, the estimated mean effects are all positive, indicating that increases in any of these variables increase total cost,

\footnotetext{
${ }^{22}$ Such an exercise is beyond the scope of the present. We leave this for future research.
} 
ceteris paribus. In contrast, for the PL model a $1 \%$ increase in equity capital is associated with a reduction in total cost by $4 \%$, on average.

It is noteworthy that all the estimated functional coefficients are well behaved as shown by their empirical distributions (Figure 1). This is particularly remarkable for the nonparametric functional coefficients of the SPG model since they are completely unconstrained.

The functional coefficients in all three models are observation-specific. Thus, we compute their standard errors using the wild bootstrap method of Hardle and Mammen (1993). Figure 2 shows the observation-specific functional coefficient estimates from the SPG model along with their 95\% confidence intervals. Unreported results show a similar pattern for the PG and PL models.

To understand these figures, consider the plot for the estimated functional coefficients $\hat{\beta}_{0}(\cdot)$ in Figure 2 . We plot $\hat{\beta}_{0}(\cdot)$ against $\hat{\beta}_{0}(\cdot)$ such that all the coefficients $\hat{\beta}_{0}(\cdot)$ lie along the $45^{\circ}$ line. The points above (below) the $45^{\circ}$ line represent the upper (lower) bound of each confidence interval. Therefore, for each $\beta_{0}(\cdot)$ on the $45^{\circ}$ line we can see an observation-specific confidence interval. If the horizontal line at zero passes inside of the confidence bounds for any given observation, then $\beta_{0}(\cdot)$ for this observation is statistically insignificant. Conversely, if the horizontal line at zero passes outside of the confidence bounds, then $\beta_{0}(\cdot)$ for this observation is statistically significant. In addition, if the lower (upper) bound lies above (below) zero, then the coefficient for this observation is significantly positive (negative). In general, the confidence intervals for each of the functional coefficients are quite tight, although they become wider at the tails.

\subsection{Returns to Scale}

We present summary statistics for RTS estimates using the SPG, PG, and PL models in Panels A, B, and C of Table 3. Figures 3 and 4 show their empirical distributions. We find economically and statistically significant scale economies for most banks. For the SPG model (Panel A), mean RTS estimates is 1.42 , indicating that if outputs were to increase by $10 \%$, total costs will increase approximately by $7 \%(10 \% \times 1 / 1.42)$. Mean RTS estimates from the PG model (Panel B) is 1.40. These results indicate presence of increasing RTS (IRTS) for most banks. The mean RTS from the PL model (Panel C) is 1.01, indicating constant RTS (CRTS). The empirical distribution of estimated RTS from the SPG or PG models show decreasing RTS for less than $2 \%$ of the observations. In contrast, estimated RTS from the PL model show DRTS for about $42 \%$ of the observations.

Estimated RTS decrease with bank size, see Table $3 .{ }^{23}$ Mean RTS for small, medium, and big

\footnotetext{
${ }^{23}$ We classify banks by total assets as follows: Big (assets $>\$ 1$ billion), medium $(\$ 100$ million $<$ assets $<\$ 1$
} 
banks are 1.56, 1.34, and 1.18 from the SPG model and 1.54, 1.32, and 1.10 from the PG model. Mean RTS for the top 100 banks are also lower than for all other banks. Estimated RTS from the SPG and PG models show that almost all medium and small banks exhibit IRTS. More than $75 \%$ of big banks and more than $50 \%$ of the top 100 banks also exhibit IRTS. Estimates RTS from the PL model show IRTS for about $50 \%$ of banks. ${ }^{24}$

The RTS estimates from the PG and the PL model are directly comparable in the sense that both models controls for fixed bank-specific effects. This is, however, not the case with the PL model. Thus the differences in RTS estimates in the PL model from the other two models might be attributed to ignoring bank-specific effects. Estimated RTS from the PL model are both statistically and economically smaller than those from the PG model, indicating that failure to account for timeinvariant unobserved heterogeneity conceals the evidence of substantial scale economies for most banks.

Now we investigate the statistical significance of our RTS estimates. In Figure 5, we depict the estimated $95 \%$ confidence intervals for RTS estimates by bank size for each model. In Table 4, we report the percentage of observations exhibiting statistically significant increasing, decreasing, or constant RTS. For each plot in Figure 5, points above (below) the $45^{\circ}$ line represent the upper (lower) bounds of observation-specific confidence intervals. Points on the $45^{\circ}$ line are the estimated RTS. If the horizontal line at one passes inside of the confidence bounds for any given observation, then RTS estimate for this observation is statistically equal to one (CRTS). If the lower (upper) bound lies above (below) one, then the RTS estimate for this observation is significantly greater (less) than one, indicating IRTS (DRTS).

The confidence intervals in Figure 5 are consistent with the existence of IRTS for most banks reported above. In the SPG model, $98 \%$ of the observations for medium and small banks show presence of IRTS. The corresponding values for big and the top one hundred banks are $75 \%$ and $65 \%$, respectively (see Table 4 ). Only $2 \%$ of the observations for medium and small banks show presence of CRTS and none shows evidence of DRTS. Only $13 \%$ of the big banks and $26 \%$ of the top one hundred banks show evidence of DRTS.

The evidence from the PG model is consistent with the results from the SPG model, except for the top one hundred banks. The estimates from the PG model show evidence of IRTS for $100 \%$, $74 \%$, and $23 \%$ of medium and small banks, big banks, and the top one hundred banks, respectively.

billion), and small (assets $<\$ 100$ million) banks. The top 100 banks correspond to the 100 biggest banks by assets each year. This classification is typically used in the literature (see Feng and Serletis, 2009)

${ }^{24}$ RTS estimates from the SPG model has more extreme values than those from the PG model. This is expected from a nonparametric model. That is, the distribution of RTS from the PG model is quite tight. 
In contrast, estimates from the PL model fail to uncover evidence of IRTS for most banks.

We plot the relation between RTS estimates and bank size in Figure 6 for the SPG and PG models. RTS estimates from the SPG and PG models decrease monotonically as bank size increases. There is a clear inverse relation between RTS and bank size - measured by size deciles. The interquartile range of RTS estimates tend to be wider for the smallest and the biggest banks. Unreported results show that the empirical distribution of bank size is almost the same for the biggest one hundred banks that exhibit either increasing or decreasing RTS. Thus, for the biggest one hundred banks (as measured by total assets) RTS estimates are unrelated to bank size, suggesting that some of these banks will continue growing irrespective of their actual size.

Based on transition probability matrices (not reported), we find that RTS estimates from the SPG model are stable over time. The likelihood of remaining within the same RTS decile or switching to the two adjacent RTS deciles are around $70 \%$ for the SPG model and $90 \%$ for the PG model. For the SPG model, the probabilities of remaining in a given decile over time or switching between adjacent deciles are lower than those for the PG model, suggesting that the RTS estimates from the PG model are more stable over time. This may stem from the parametric assumptions underlying the PG model. In contrast, the SPG model RTS estimates are fully nonparametric. Nonetheless, the probabilities of switching across deciles that are farther away from each other are small for both models, indicating that there are no large swings on the estimated RTS. Unreported piece-wise Spearman rank correlations show that the rank correlation for adjacent years are high for both the SPG and the PG model (above 0.75 and 0.98, respectively). These results are consistent with the transition probabilities matrix results discussed before and may stem from the fact that the parametric specification imposes stronger restrictions on the dynamics of RTS estimates in contrast to the fully nonparametric RTS estimates from the SPG model.

\subsection{TFP Growth and Its Components}

We compute TFP growth (the Divisia) from $T \dot{F} P \equiv \sum_{q=1}^{Q} R_{q} \dot{Y}_{q}-\sum_{k=1}^{K} S_{k} \dot{X}_{k}$. Note that the Divisia can be computed directly from the data without estimating any econometric model. In order to decompose it into technical change, scale, allocative, exogenous, and random components using (11), we need to estimate the components econometrically. That is, in an econometric model one estimates the components and then add them to compute TFP growth. The results are presented in Table 5. The first row of each panel corresponds to the estimated TFP annual growth rate. Since the SPG and PG models use growth formulation, TFP growth rates differ from the Divisia TFP growth rate only by the random component which has a zero mean. This is why TFP growth 
obtained from adding the components equals the Divisia. This is, however, not the case in the PL model in which the error term is not the same as the last component of TFP growth in (11)..$^{25}$

Average annual TFP growth rate is $3.1 \%$ with a standard deviation of $8.3 \%$. Average TFP growth using either the SPG or the PG model equals the average Divisia TFP growth rate but its standard deviation is lower, reflecting the absence of the random component. Average TFP annual growth rate using the PL model is $1.1 \%$ with a standard deviation of $8.4 \%$. Since the the PL model uses data in logs, it fits total cost changes less accurately, resulting in a large unexplained component (which is zero on average in both the SPG and PG models). Thus, TFP growth rate estimates from the PL model is likely to differ from the Divisia TFP growth rates. ${ }^{26}$

The top left panel of Figure 8 shows estimated average annual TFP growth rate over time for the Divisia and the three econometric models. TFP growth rates are positive over the sample period for the Divisia, the SPG and PG models. After a slight deceleration from 2002 to 2006, TFP growth grew sharply from 2007 to 2010. This result holds for the Divisia and the SPG and PG models. In contrast, TFP growth rate estimates using the PL model overestimate the deceleration from 2002 to 2006 and underestimate TFP growth from 2007 onwards. Compared with 2001 levels, the TFP indexes for the Divisia and the SPG and PG models increase about 33\% by 2010 (see the top right plot in Figure 8). The PL model's TFP index shows that the increase was only about $11 \%$. SPG model's average annual TFP growth rate for big, medium, and small banks are 3.9\%, 3.1\%, and $3 \%$, respectively. For the PG model, the corresponding values are 3.3\%, 3.3\%, and 2.9\%; and for the PL model they are $1.6 \%, 1 \%$, and $1.1 \%$.

Taken together, these results suggest that estimating the underlying parameters of the cost function without controlling for unobserved heterogeneity may lead to biased TFP growth components. In particular, in the PL model the mean difference between the annual total cost change and its estimate is $-2 \%$. This is exactly the difference between the average TFP growth estimated from the PL model and the Divisia. Therefore, without controlling for time-invariant unobserved heterogeneity, the parameter estimates of the underlying cost function are biased. As a consequence, the PL model attributes most of the TFP growth to the random component.

Now we focus on the sources of TFP growth by examining each component separately.

\footnotetext{
${ }^{25}$ See Kumbhakar and Sun, 2012, for a discussion on this issue based on an input distance function formulation.

${ }^{26}$ This finding is not new in the TFP growth literature. For example, see Kumbhakar and Lozano-Vivas (2005) and the references cited in there.
} 


\subsubsection{Scale Economies}

The scale component of TFP in (11), $\sum_{q=1}^{Q}\left(R_{q}-\gamma_{q}\right) \dot{Y}_{q}$ can be rewritten as $(R T S-1) \sum_{q=1}^{Q} \gamma_{q}(\cdot) \dot{Y}_{q}+$ $\sum_{q=1}^{Q}\left(R_{q}-\gamma_{q}(\cdot) / \Gamma(\cdot)\right) \dot{Y}_{q}$ where $\Gamma(\cdot)=\sum_{q} \gamma_{q}(\cdot)$. The presence of scale economies (IRTS) contributes positively to TFP growth if output growth rates $\left(\dot{Y}_{q}\right)$ weighted by the elasticity of cost with respect to each output $\left(\gamma_{q}\right)$ is positive. If the marginal cost for each output equals the corresponding output price, then $R_{q}=\gamma_{q} / \Gamma_{q}$ which means $\sum_{q=1}^{Q}\left(R_{q}-\gamma_{q} / \Gamma_{q}\right) \dot{Y}_{q}=0$. If not, this component will be nonzero and can be interpreted as the mark-up component. The means of this mark-up component for the SPG, PG, and PL models are $0.6 \%, 0.3 \%$, and $0.2 \%$, respectively.

The mean of the scale component equals $2.2 \%, 1.8 \%$, and $0.2 \%$ for the SPG, PG, and PL models, respectively. Thus, on average, economies of scale contribute positively to TFP growth. Compared with medium and small banks, the contribution of scale economies to TFP growth is higher for big banks.

The positive contribution indicates that, on average, $R_{q}-\gamma_{q}(\cdot) \geq 0$, which means that the effects of output price changes on total revenue are higher than the corresponding effects of output quantity changes on cost (i.e., a $1 \%$ change in a given output causes a proportional change in total cost that is lower than the proportional change in total revenue caused by a $1 \%$ increase in the corresponding output price.)

The right-middle plot of Figure 8 shows that the scale component for the SPG and PG models are similar. The SPG scale component tends to grow faster, however, reflecting the higher RTS obtained using the SPG model. This plot also shows that the differences in estimated RTS between the SPG and PG model are small and their contributions to TFP growth are comparable.

Our results strongly support the hypothesis that most U.S. commercial banks enjoy substantial economies of scale. Our nonparametric RTS estimates (SPG model) indicate that, on average, more than $98 \%$ of banks experience increasing RTS. We reject the hypothesis of increasing RTS for $26 \%$ of the observations for the biggest U.S. banks. The evidence in favor of increasing RTS is even stronger using the parametric growth model (PG model).

\subsubsection{Technical Change}

From (11), the contribution of TC to TFP growth is $-\beta_{0}(\cdot)=-\partial \hat{f} / \partial t$. Estimates of TC from the SPG and the PG models show an annual rate of technical change about $-0.1 \%$ and $1 \%$, respectively (see Table 2). Results from these two models also show that big banks experience higher rates of TC than medium and small banks. Mean TC from the SPG model are $0.6 \%,-0.1 \%$, and $-0.1 \%$, for big, medium, and small banks, respectively. The corresponding values from the PG model are 
$1.7 \%, 0.9 \%$, and $1 \%$.

These differences lead to different temporal paths of TC as shown in the left-middle plot of Figure 8. Estimates of TC from the PG model show that banks experience substantial gains in TFP growth. The SPG model suggests that total cost remains essentially unchanged from 2001 to 2010 , ceteris paribus. Given that the SPG model imposes fewer constraints on the model and therefore on the dynamics of TC, we take the results from this model more seriously.

\subsubsection{Allocative Component}

TFP growth is also affected by deviations of actual input shares, $S_{k}$, from the optimal input shares, $\beta_{k}$. This happens when banks fail to use inputs optimally. The allocative component, $A L=\sum_{k=1}^{K-1}\left(S_{k}-\beta_{k}\right) \dot{\vec{W}}_{k}$, captures the contribution of such input misallocations (over- or underuse of inputs) on TFP growth. If $S_{k}=\beta_{k}, k=1, \ldots, 4$, then there is no input mis-allocation and therefore $A L=0$. The sign on $A L$ depends on the extent of input mis-allocation as well as rate of change in relative input prices.

The average contribution of AL in the SPG and PG models are $1.7 \%$ and $0.7 \%$, with standard deviation of $4.2 \%$ and $3.8 \%$. For the PL model it is $0.8 \%$ with a standard deviation of $5.7 \%$. Figure 8 shows the temporal behavior of AL in the three models. The AE component from the SPG model shows an increase of about $17 \%$ during 2001 to 2010. The corresponding values for the PG and PL models are about $6 \%$ and 7\%, respectively. The AE component from the SPG model show a steady increase during the sample period. On the other hand, the PG and PL models show increases up to 2004, decreases for 2005 and 2006, and steady gains thereafter. The estimates from all three models indicate allocative efficiency gains from 2007 to 2010.

Gains from AL predicted by the SPG model are 2\% for big banks, $1.6 \%$ for medium, and $1.8 \%$ for small banks. The corresponding values from the PG model are $0.8 \%, 0.7 \%$, and $0.7 \%$, respectively. In contrast, the estimates from the PL model are about $0.8 \%$ regardless of bank size.

\subsubsection{Exogenous Component}

TFP growth can also be affected by factors other than technical change, allocative efficiency, and scale economies. We consider three such factors, viz., $(\log )$ equity capital $\left(Z_{1}\right)$, non-traditional activities (off-balance sheet activities: $Z_{2}$ ), and non-performing loans $\left(Z_{3}\right)$. The contribution of exogenous component $E X=-\sum_{p=1}^{P} \varphi_{p}(\cdot) \nabla_{t} Z_{p}$ in (11) captures this. The EX values for the SPG and PG models follow a similar pattern over time. Average values of EX from the SPG and PG models are small but negative, $-0.7 \%$ and $-0.4 \%$, with standard deviations of $2.5 \%$ and $1.2 \%$, 
respectively. Thus, these exogenous factors contribute negatively to TFP growth. However, their effects are small compared with the other components. The last plot in Figure 8 shows that the cumulative effect of the exogenous factors for the 2001 to 2010 period based on the SPG model is about $-6 \%$ and is about $-3 \%$ predicted by the PG model. On the other hand, the PL model show that EX component contributed positively to TFP growth.

We now summarize the results of the preceding section on the importance of various components of TFP growth. According to the SPG and the PG model, the main contributing component to TFP growth is the scale component. The second largest component is the allocative component for the SPG model and the technical change component for the PG model. Finally, the exogenous component contributes little to TFP growth.

TFP grew about 33\% during 2001 to 2010. According to the SPG model TC contributed negatively by $0.5 \%$, scale economies positively by $21.5 \%$, allocative efficiency by $17.3 \%$ and the exogenous factors contributed negatively by $6 \%$ due to component. For the PG model the contributions are: TC 9.5\%, scale economies $17.9 \%$, allocative efficiency $7.5 \%$, exogenous factors $-4 \%$. According to the PL model, TFP grew only by $11.6 \%$ during 2001 to 2010 . The contributions are: TC $-0.5 \%$, scale economies $1.8 \%$, allocative efficiency $9 \%$, and exogenous factors $0.78 \%$.

The trend of TFP growth for big, medium, and small banks is similar. However, big banks experience sharper swings in TFP growth than medium and small banks. TFP grew steadily for all banks from 2001 to 2010 with some periods of deceleration. TFP grew 44.6\%, 32.2\%, and 32.3\% for big, medium, and small banks. During 2008 to 2010, TFP growth for big banks was 1.5 times faster than the medium and small banks.

\section{Comparison with the recent empirical literature}

Although our approach differs from previous studies but our results are broadly consistent with most of the recent literature reviewed in Section 2. We limit our comparison of RTS results to Wheelock and Wilson (2012) since our model is almost identical to theirs and our RTS measures are also nonparametric functions of the determinants of banks' total costs. Thus any differences between our results and those in Wheelock and Wilson are likely to be driven by the use of different estimation methods and sample periods. Our method, however, offers some advantages over Wheelock and Wilson's approach that make our evidence more compelling. Our theoretical framework and our econometric model exploit the underlying dynamics of changes in total costs and its determinants. Thus, our estimation strategy automatically account for cost variation over time for 
each individual bank. Further, our RTS measures arise naturally within that theoretical framework and correspond to the most widely accepted definition of RTS used in the literature. In contrast, Wheelock and Wilson's approach is theoretically static and their estimation strategy assumes that observations for a given bank are independent over time. Unlike Wheelock and Wilson's method, our approach controls for time-invariant unobserved heterogeneity across banks. In addition, our econometric model is simpler and easier to estimate than the one used by Wheelock and Wilson.

Contrary to Wheelock and Wilson (2012) who find evidence of IRTS for all banks, our results suggest that not all U.S. commercial banks enjoy economies of scale. Although most banks exhibit increasing RTS, some of the biggest banks, specially those among the top one hundred banks, experience constant or slightly decreasing RTS. These differences in results may stem from the slightly different model of bank costs that we use. Wheelock and Wilson (2012) assume that physical capital is a quasi-fixed input. In contrast, we assume that physical capital is a variable input. Caves, Christensen, and Swanson (1981) derive a measure of RTS to account for the quasi fixity of inputs. They show that the correct measure of RTS have to be adjusted by the elasticity of variable costs with respect to quasi-fixed input quantities. When this elasticity is greater (less) than zero, the shadow price of the quasi-fixed input is greater (less) than its market price, implying excess capacity with respect the quasi-fixed input (see Morrison 1985 and Morrison and Siegel 1999). With excess capacity, the traditional measures of RTS, which only accounts for variable inputs, are biased upward. Since Wheelock and Wilson (2012) did not adjust their RTS estimates to accommodate quasi fixity of physical capital, the more likely explanation is that their RTS estimates may be biased upward.

Using the PL and PG models, we re-estimate our measure of RTS assuming that physical capital is quasi-fixed as in Wheelock and Wilson (2012). Based on these (unreported) results, we find that the elasticity of variable costs with respect to physical capital is positive, indicating excess capacity with respect physical capital. Therefore, without accounting for quasi-fixity in the computation of RTS, these estimates will be upwardly biased. We find that without adjusting for excess capacity, the traditional measure of RTS give estimates that are about $15 \%$ higher than our previous estimates for the PL model and $6.5 \%$ for the PG model. However, after adjusting for the quasi fixity of physical capital, the estimates are almost identical to our previous estimates for the PL model and about $25 \%$ lower for the PG model. Our evidence suggest that Wheelock and Wilson (2012)'s results are upwardly biased.

Our finding that economies of scale decrease monotonically as bank size increases indicates 
that economies of scale tend to be exhausted as banks grow. However, the process is slow and the size level at which economies of scale cease to drive bank grow differ across the biggest banks. In addition, since economies of scale are unrelated to total assets for the biggest one hundred banks, total assets may be a poor measure of bank size for these banks.

The differences between our nonparametric and parametric results from the SPG and PG models indicate that using parametric functional forms for the cost function restricts the dynamics of RTS estimates. Thus, we favor the use of nonparametric models when possible. Using the PG model, RTS show little heterogeneity over time. In contrast, the nonparametric RTS estimates, which are fully flexible, show substantial heterogeneity over time.

Unlike previous studies, our framework allows us to tie the functional coefficients of our models to TFP growth components, allowing us to investigate the main forces explaining U.S. banking industry growth. Our results show that increasing returns to scale played an important role in explaining growth of U.S. banking industry. By comparison, the role of technical change is smaller. Our results are consistent with the recent evidence presented by Diewert and Fox (2008) for the U.S. manufacturing industry. In contrast, Feng and Serletis (2010) find that technical change is the main driver of TFP growth during 2000 to 2005.

\section{Policy Implications}

Despite the wide range of problems recently addressed by enacted financial regulations in the U.S., policymakers, regulators, academics, and financial market participants are still pondering the idea of capping the size of banks, bringing the issue of existence of scale economies to the fore of the policy debate. If big banks enjoy substantial scale economies, breaking up the biggest banks or capping their size may impose efficiency losses for the economy. For instance, Wheelock and Wilson (2012) estimate that the cost of breaking the four largest U.S. bank holding companies in existence in 2010 would exceed their combined net income in each year from 2003 to 2006. On the other hand, Boyd and Heitz (2012) estimates that the potential benefits to the society from economies of scale of big financial institutions are unlikely to ever exceed the potential costs due to increased risk of financial crisis.

Our results have important implications on this debate. First, contrary to Wheelock and Wilson (2012), our findings suggest that the cost of breaking up big banks may be lower than their estimate since not all the biggest banks enjoy economies of scale. Despite the existence of scale economies for most banks with assets in excess of $\$ 1$ billion, scale economies seem to be exhausted or may 
be unrelated to bank size between $\$ 5$ and $\$ 30$ billions of assets. Therefore, the potential benefits of scale economies for big commercial banks may be limited.

Second, our results indicate that scale economies are likely to continue to be the major driver of growth for small, medium, and some of the biggest banks. We find that scale economies contribute significantly to TFP growth, giving strong incentives for banks to keep growing. Thus, any attempt to cap the size of banks will likely encounter strong opposition. Without imposing endogenous regulatory constraints that increase the marginal cost for banks from getting bigger, the average size of banks will continue to increase. Higher capital requirements for larger and more systematically important banks are likely to be more effective than capping the size of banks. As size and complexity increase, further regulatory burden and enhanced disclosure requirements for the biggest banks may serve as an additional deterrent to keep them from getting even bigger.

Third, consolidation of small and medium banks and further growth of some of the biggest banks pose big challenges to regulators. Future failures will likely involve, on average, a greater number of bigger and more interconnected banks. As overall bank size increases, the likelihood of widespread bank failures also increases. Therefore, regulators should widen the focus of their efforts to cover not only the top bank holding companies but also the increasing number of big banks. In addition, larger average size of banks means stronger barriers to entry for potential competitors which can greatly affect concentration, competition, and efficiency.

\section{Conclusions}

In this paper we focused on estimation of returns to scale, TFP growth and its components (technical change, scale, exogenous factors) for U.S. commercial banks during 2001 to 2010. The main innovation of our approach is that we start from a nonparametric cost function and control for bank-specific fixed effects; a feature absent in previous studies for the U.S. banking industry. The semiparametric smooth coefficient (SPSC) model we used arises naturally from the underlying nonparametric cost function upon total differentiation with respect to time. This growth-based approach allows us to better account for the dynamic evolution of banks' production technologies over time.

Another distinctive feature of our approach is that the functional coefficients of the SPSC model are nonparametric functions of the arguments of the cost function, and are not ad hoc. In our case, the SPSC model shares the main advantages of a fully nonparametric approach, exploits the dynamic structure of the data, and gives us fully nonparametric estimates of RTS and TFP growth 
components.

We also use parametric translog cost specifications with and without fixed bank-effects. This strategy allows us to compare RTS estimates and TFP growth components across parametric and nonparametric models.

The main conclusion we drew from the study is that more than $98 \%$ of banks still enjoy economies of scale, and more than $73 \%$ of the biggest banks exhibit increasing RTS. We find that RTS estimates from the semiparametric and parametric growth models decrease monotonically across bank size deciles: small banks exhibited higher scale economies than medium and large banks. The relation between mean scale economies estimates and bank size is L-shaped across bank size deciles; indicating that after certain threshold, increases in bank size reduce scale economies only slightly. Thus, further increase in average bank size is likely; either through internally generated growth or through merger and acquisitions.

Our findings also show that failing to control for unobserved heterogeneity across banks is likely to conceal evidence of increasing RTS. In contrast to the SPSC and parametric growth models, which control for unobserved heterogeneity across banks, the RTS estimates from the standard translog model show scant evidence of scale economies. In this case, only small banks exhibit increasing RTS and most medium and large banks show either constant or decreasing RTS.

Unlike previous studies, we find that the major drivers of TFP growth are scale and allocative components. Technical change and other exogenous components, like changes in loan quality, risk, and off-balance sheet activities, affect TFP growth only marginally. This reinforces our main conclusions that banks still have incentives to continue growing: doing so contributes to TFP growth positively and significantly.

\section{References}

Allen, J., Liu, Y., 2007. Efficiency and economies of scale of large Canadian banks. Canadian Journal of Economics/Revue canadienne d'conomique 40 (1), 225-244.

Amel, D., Barnes, C., Panetta, F., Salleo, C., 2004. Consolidation and efficiency in the financial sector: A review of the international evidence. Journal of Banking \& Finance 28 (10), 2493 - 2519.

Bartelsman, E. J., Doms, M., 2000. Understanding Productivity: Lessons from Longitudinal Microdata. Journal of Economic Literature 38 (3), 569.

Bauer, P., Berger, A., Humphrey, D., 1993. Efficiency and productivity growth in US banking. In: Fried, H., Lovell, C., S., S. (Eds.), The measurement of productive efficiency: Techniques and applications. Oxford University Press, New York, pp. 386-413. 
Berger, A. N., Demsetz, R. S., Strahan, P. E., 1999. The consolidation of the financial services industry: Causes, consequences, and implications for the future. Journal of Banking \&amp; Finance 23 (24), 135 - 194.

Berger, A. N., Hanweck, G. A., Humphrey, D. B., 1987. Competitive viability in banking: Scale, scope, and product mix economies. Journal of Monetary Economics 20 (3), 501 - 520.

Berger, A. N., Humphrey, D., 1994. Bank Scale Economies, Mergers, Concentration, and Efficiency: The US Experience. Center for Financial Institutions Working Papers.

Berger, A. N., Mester, L. J., 1997. Inside the Black Box: What Explains Differences in the Efficiencies of Financial Institutions? Journal of Banking \& Finance 21 (7), 895 - 947.

Berger, A. N., Mester, L. J., 2003. Explaining the Dramatic Changes in Performance of US banks: Technological Change, Deregulation, and Dynamic Changes in Competition. Journal of Financial Intermediation 12 (1), 57 - 95.

Boyd, J., Heitz, A., 2012. The Social Costs and Benefits of Too-Big-To-Fail Banks: A "Bounding” Exercise. Tech. rep., University of Minnesota.

Caves, D. W., Christensen, L. R., Swanson, J. A., 1981. Productivity Growth, Scale Economies, and Capacity Utilization in U.S. Railroads, 1955-74. The American Economic Review 71 (5), pp. 994-1002.

Clark, J. A., 1988. Economies of scale and scope at depository financial institutions: A review of the literature. Economic Review 73 (8), 17-33.

Clark, J. A., 1996. Economic Cost, Scale Efficiency, and Competitive Viability in Banking. Journal of Money, Credit and Banking 28 (3), pp. 342-364.

Daniels, K. N., Tirtiroglu, D., 1998. Total Factor Productivity Growth in U.S. Commercial Banking for 19351991: A Latent Variable Approach Using the Kalman Filter. Journal of Financial Services Research 13, 119-135, 10.1023/A:1007922103037.

Das, A., Kumbhakar, S., 2012. Productivity and Efficiency Dynamics in Indian Banking: an Input Distance Function Approach Incorporating Quality of Inputs and Outputs. Journal of Applied Econometrics.

Denny, M., Fuss, M., Waverman, L., 1979. Productivity Measurement in Regulated industries. Academic Press, Ch. The measurement and interpretation of total factor productivity in regulated industries, with an application to Canadian telecommunications, pp. 179-212.

Diewert, W. E., Fox, K. J., 2008. On the estimation of returns to scale, technical progress and monopolistic markups. Journal of Econometrics 145 (12), 174 - 193.

Feng, G., Serletis, A., 2009. Efficiency and productivity of the US banking industry, 1998-2005: evidence from the Fourier cost function satisfying global regularity conditions. Journal of Applied Econometrics 24 (1), $105-138$.

Feng, G., Serletis, A., 2010. Efficiency, technical change, and returns to scale in large US banks: Panel data evidence from an output distance function satisfying theoretical regularity. Journal of Banking \& Finance 34 (1), 127 - 138.

Feng, G., Zhang, X., 2012. Productivity and efficiency at large and community banks in the US: A Bayesian true random effects stochastic distance frontier analysis. Journal of Banking \& Finance Forthcoming (0).

Greene, W., 2005a. Fixed and Random Effects in Stochastic Frontier Models. Journal of Productivity Analysis 23, 7-32, 10.1007/s11123-004-8545-1.

Greene, W., 2005b. Reconsidering heterogeneity in panel data estimators of the stochastic frontier model. Journal of Econometrics 126 (2), 269 - 303.

Hardle, W., Mammen, E., 1993. Comparing Nonparametric Versus Parametric Regression Fits. The Annals of Statis- 
tics 21 (4), pp. 1926-1947.

Hayfield, T., Racine, J. S., 2008. Nonparametric Econometrics: The np Package. Journal of Statistical Software 27 (5).

Hughes, J., Mester, L., 1998. Bank capitalization and cost: Evidence of scale economies in risk management and signaling. Review of Economics and Statistics 80 (2), 314-325.

Hughes, J. P., Lang, W., Mester, L. J., Moon, C.-G., 1996. Efficient Banking under Interstate Branching. Journal of Money, Credit and Banking 28 (4), pp. 1045-1071.

Hughes, J. P., Lang, W., Mester, L. J., Moon, C.-G., 2000. Recovering Risky Technologies Using the Almost Ideal Demand System: An Application to U.S. Banking. Journal of Financial Services Research 18, 5-27, 10.1023/A:1026554922476.

Hughes, J. P., Mester, L. J., 2010. Efficiency in Banking: Theory, Practice, and Evidence. In: Berger, A., Molyneux, P., Wilson, J. (Eds.), The Oxford Handbook of Banking. Oxford University Press, New York, Ch. 19.

Hughes, J. P., Mester, L. J., 2011. Who said large banks don't experience scale economies? Evidence from a riskreturn-driven cost function. Working Papers 11-27, Federal Reserve Bank of Philadelphia.

Hughes, J. P., Mester, L. J., Moon, C.-G., 2001. Are scale economies in banking elusive or illusive?: Evidence obtained by incorporating capital structure and risk-taking into models of bank production. Journal of Banking \& Finance 25 (12), $2169-2208$.

Humphrey, D., 1992. Flow versus stock indicators of banking output: effects on productivity and scale economy measurement. Journal of Financial Services Research 6 (2), 115-135.

Humphrey, D. B., 1991. Productivity in banking and effects from deregulation. Economic Review 1 (Mar), 16-28.

Humphrey, D. B., 1993. Cost and Technical Change: Effects from Bank Deregulation. Journal of Productivity Analysis $4(1 / 2), 9-34$.

Hunter, W. C., Timme, S. G., 1986. Technical Change, Organizational Form, and the Structure of Bank Production. Journal of Money, Credit and Banking 18 (2), pp. 152-166.

Hunter, W. C., Timme, S. G., 1991. Technological Change in Large U.S. Commercial Banks. The Journal of Business 64 (3), pp. 339-362.

Johnson, S., December 2012. Tarullo Telegraphs Fed's Plans to Cap Bank Size. Bloomberg News' Column.

Kumbhakar, S., Lien, G., Flaten, O., Tveterås, R., 2008. Impacts of Norwegian Milk Quotas on Output Growth: A Modified Distance Function Approach. Journal of Agricultural Economics 59 (2), 350-369.

Kumbhakar, S., Lozano-Vivas, A., 2005. Deregulation and productivity: The case of Spanish banks. Journal of Regulatory Economics 27 (3), 331-351.

Kumbhakar, S., Sun, K., 2012. Estimation of TFP growth: a semiparametric smooth coefficient approach. Empirical Economics Forthcoming, 1-24.

Li, Q., Huang, C. J., Li, D., Fu, T.-T., 2002. Semiparametric Smooth Coefficient Models. Journal of Business \& Economic Statistics 20 (3), pp. 412-422.

Li, Q., Racine, J., 2007. Nonparametric econometrics: Theory and Practice. Princeton University Press.

Li, Q., Racine, J. S., 2010. Smooth Varying-Coefficient Estimation and Inference for Qualitative and Quantitative Data. Econometric Theory 26 (06), 1607-1637.

Mester, L. J., 1994. How efficient are third district banks? Business Review 1994, 1-3.

Mester, L. J., 1996. A study of bank efficiency taking into account risk-preferences. Journal of Banking \& Finance 
$20(6), 1025-1045$.

Mester, L. J., 1997. Measuring efficiency at U.S. banks: Accounting for heterogeneity is important. European Journal of Operational Research 98 (2), 230 - 242.

Morrison, C. J., 1985. Primal and Dual Capacity Utilization: An Application to Productivity Measurement in the U.S. Automobile Industry. Journal of Business \& Economic Statistics 3 (4), pp. 312-324.

Morrison, C. J., Siegel, D. S., 1999. Scale Economies and Industry Agglomeration Externalities: A Dynamic Cost Function Approach. The American Economic Review 89 (1), pp. 272-290.

Mukherjee, K., Ray, S. C., Miller, S. M., 2001. Productivity growth in large US commercial banks: The initial postderegulation experience. Journal of Banking \& Finance 25 (5), 913 - 939.

Restrepo, D., Kumbhakar, S., 2011. Measuring Profit Efficiency without Estimating a Profit Function: The case of U.S. Commercial Banks. Working Paper. Binghamton University.

Robinson, P., 1988. Root-N-consistent Semiparametric Regression. Econometrica: Journal of the Econometric Society, 931-954.

Rogers, K., 1998. Nontraditional Activities and The Efficiency of US Commercial Banks. Journal of Banking \& Finance 22 (4), 467-482.

Semenick Alam, I. M., 2001. A Nonparametric Approach for Assessing Productivity Dynamics of Large U.S. Banks. Journal of Money, Credit and Banking 33 (1), pp. 121-139.

Shaffer, S., 1994. A revenue-restricted cost study of 100 large banks. Applied Financial Economics 4 (3), $193-205$.

Stern, G., Feldman, R., 2009. Addressing TBTF by shrinking financial institutions: An initial assessment. Federal Reserve Bank of Minneapolis: The Region, June, 8-13.

Stiroh, K. J., 2000. How Did Bank Holding Companies Prosper in the 1990s? Journal of Banking \& Finance 24 (11), $1703-1745$.

Syverson, C., 2011. What Determines Productivity?. Journal of Economic Literature 49 (2), 326 - 365.

Tirtiroglu, D., Daniels, K. N., Tirtirogu, E., 2005. Deregulation, Intensity of Competition, Industry Evolution, and the Productivity Growth of U.S. Commercial Banks. Journal of Money, Credit and Banking 37 (2), pp. 339-360.

Wang, H.-J., Ho, C.-W., 2010. Estimating fixed-effect panel stochastic frontier models by model transformation. Journal of Econometrics 157 (2), 286-296.

Wheelock, D. C., Wilson, P. W., 1999. Technical Progress, Inefficiency, and Productivity Change in U.S. Banking, 1984-1993. Journal of Money, Credit and Banking 31 (2), pp. 212-234.

Wheelock, D. C., Wilson, P. W., 2001. New evidence on returns to scale and product mix among U.S. commercial banks. Journal of Monetary Economics 47 (3), 653 - 674.

Wheelock, D. C., Wilson, P. W., 2011. Are credit unions too small? Review of Economics and Statistics 93 (4), 1343-1359.

Wheelock, D. C., Wilson, P. W., 2012. Do Large Banks Have Lower Costs? New Estimates of Returns to Scale for U.S. Banks. Journal of Money, Credit and Banking 44 (1), 171 - 199. 
Tables and Figures 
Table 1: Summary Statistics, 2001-2010

\begin{tabular}{|c|c|c|c|c|c|c|c|}
\hline \multirow[b]{2}{*}{ Variable } & \multirow[b]{2}{*}{ Mean } & \multirow[b]{2}{*}{ sd } & \multicolumn{5}{|c|}{ Percentiles } \\
\hline & & & $5^{\text {th }}$ & $25^{\text {th }}$ & $50^{t h}$ & $75^{\text {th }}$ & $95^{\text {th }}$ \\
\hline$Y_{1}$ & 70,358 & $1,700,000$ & 81.50 & 655.7 & 4,532 & 46,077 & $137,000,000$ \\
\hline$Y_{2}$ & 360,000 & $5,390,000$ & 1,177 & 5,683 & 49,638 & 546,000 & $404,000,000$ \\
\hline$Y_{3}$ & 220,000 & $4,740,000$ & 713.5 & 2,953 & 17,131 & 166,000 & $348,000,000$ \\
\hline$Y_{4}$ & 291,000 & $7,950,000$ & 826.4 & 4,601 & 27,012 & 247,000 & $782,000,000$ \\
\hline$Y_{5}$ & 38,042 & $1,010,000$ & 95.62 & 308.0 & 1,595 & 17,445 & $89,500,000$ \\
\hline$X_{1}$ & 226 & 3,476 & 3.000 & 8.500 & 36.25 & 296.75 & 214,000 \\
\hline$X_{2}$ & 11,686 & 146,000 & 4.000 & 151.80 & 2,022 & 19,613 & $10,500,000$ \\
\hline$X_{3}$ & 290,000 & $6,670,000$ & 24.628 & 2,519 & 21,474 & 272,000 & $540,000,000$ \\
\hline$X_{4}$ & 26,307 & 247,000 & 56.084 & 1,757 & 10,096 & 53,636 & $20,000,000$ \\
\hline$X_{5}$ & 545,000 & $11,000,000$ & 1,025 & 10,929 & 50,047 & 585,000 & $763,000,000$ \\
\hline$W_{1}$ & 52.54 & 12.99 & 23.91 & 36.47 & 49.99 & 77.82 & 117.1 \\
\hline$W_{2}$ & 0.346 & 0.338 & 0.052 & 0.104 & 0.241 & 0.955 & 3.406 \\
\hline$W_{3}$ & 0.034 & 0.011 & 0.008 & 0.017 & 0.034 & 0.053 & 0.064 \\
\hline$W_{4}$ & 0.010 & 0.007 & 0.001 & 0.002 & 0.008 & 0.025 & 0.042 \\
\hline$W_{5}$ & 0.026 & 0.010 & 0.004 & 0.011 & 0.025 & 0.046 & 0.055 \\
\hline$R$ & 71,765 & $1,300,000$ & 234 & 1,792 & 8,290 & 78,874 & $83,600,000$ \\
\hline$R_{1}$ & 0.065 & 0.058 & 0.000 & 0.007 & 0.051 & 0.171 & 0.913 \\
\hline$R_{2}$ & 0.416 & 0.165 & 0.000 & 0.149 & 0.414 & 0.693 & 0.943 \\
\hline$R_{3}$ & 0.205 & 0.147 & 0.000 & 0.040 & 0.164 & 0.511 & 0.915 \\
\hline$R_{4}$ & 0.153 & 0.106 & 0.000 & 0.027 & 0.129 & 0.358 & 0.961 \\
\hline$R_{5}$ & 0.161 & 0.088 & 0.001 & 0.049 & 0.148 & 0.312 & 0.920 \\
\hline$C$ & 39,045 & 758,000 & 237 & 978 & 4,678 & 43,661 & $54,100,000$ \\
\hline$S_{1}$ & 0.413 & 0.108 & 0.026 & 0.247 & 0.407 & 0.599 & 0.877 \\
\hline$S_{2}$ & 0.103 & 0.041 & 0.001 & 0.046 & 0.099 & 0.177 & 0.393 \\
\hline$S_{3}$ & 0.166 & 0.089 & 0.000 & 0.046 & 0.154 & 0.326 & 0.907 \\
\hline$S_{4}$ & 0.026 & 0.028 & 0.000 & 0.002 & 0.017 & 0.078 & 0.447 \\
\hline$S_{5}$ & 0.292 & 0.104 & 0.011 & 0.131 & 0.285 & 0.473 & 0.958 \\
\hline$S Y_{1}$ & 0.058 & 0.053 & 0.000 & 0.006 & 0.045 & 0.153 & 0.879 \\
\hline$S Y_{2}$ & 0.458 & 0.173 & 0.000 & 0.169 & 0.460 & 0.736 & 0.946 \\
\hline $\mathrm{SY}_{3}$ & 0.187 & 0.115 & 0.000 & 0.046 & 0.161 & 0.416 & 0.931 \\
\hline$S Y_{4}$ & 0.281 & 0.152 & 0.002 & 0.074 & 0.257 & 0.567 & 0.960 \\
\hline$S Y_{5}$ & 0.016 & 0.009 & 0.001 & 0.008 & 0.015 & 0.029 & 0.275 \\
\hline$S Y_{123}$ & 0.703 & 0.152 & 0.024 & 0.418 & 0.726 & 0.910 & 0.991 \\
\hline$Z_{1}$ & 9.513 & 1.192 & 6.170 & 7.903 & 9.373 & 11.55 & 18.85 \\
\hline$Z_{2}$ & 0.059 & 0.065 & 0.000 & 0.008 & 0.040 & 0.166 & 0.882 \\
\hline$Z_{3}$ & 0.009 & 0.015 & 0.000 & 0.000 & 0.005 & 0.033 & 0.472 \\
\hline Total Assets & $1,050,000$ & $21,000,000$ & 5,888 & 25,382 & 115,000 & $1,080,000$ & $1,520,000,000$ \\
\hline
\end{tabular}

This table shows the average (Mean), standard deviation (sd), the minimum (min) and maximum (max), the median, and the 5 and 95 percentiles (p5 and p95, respectively). All nominal variables are measured in thousands of 2005 U.S. dollars. The data used for estimation include 60,868 yearbank observations for 7,473 different banks. The output variables are: household and individual loans $\left(Y_{1}\right)$, real estate loans $\left(Y_{2}\right)$, loans to business and other institutions $\left(Y_{3}\right)$, federal funds sold and securities purchased under agreements to resell $\left(Y_{4}\right)$, and other assets $\left(Y_{5}\right)$. The input variables are: labor quantity $\left(X_{1}\right)$, premises and fixed assets $\left(X_{2}\right)$, purchased funds $\left(X_{3}\right)$, interest-bearing transaction accounts $\left(X_{4}\right)$, and non-transaction accounts $\left(X_{5}\right)$. For each input $X_{j}$ its price, $W_{j}$, is computed by dividing total expenses by the corresponding input quantity. Rev is total revenues, and $R_{q}$ represents the revenue shares for each output category. Likewise, $S_{k}$ represents cost shares for each input category and $S Y_{q}$ represents output share for each output category. $S Y_{123}=\left(Y_{1}+Y_{2}+Y_{3}\right) /\left(Y_{1}+Y_{2}+\right.$ $Y_{3}+Y_{4}+Y_{5}$ ). $Z_{1}$ is $\log$ of equity, $Z_{2}$ is a proxy for off-balance sheet activities (noninterest income over total income), and $Z_{3}$ equals nonperforming loans over total assets. 
Table 2: Estimated Functional Coefficients

\begin{tabular}{|c|c|c|c|c|c|c|c|}
\hline \multirow[b]{2}{*}{ Parameter } & \multirow[b]{2}{*}{ Mean } & \multirow[b]{2}{*}{ sd } & \multicolumn{5}{|c|}{ Percentiles } \\
\hline & & & $5^{\text {th }}$ & $25^{\text {th }}$ & $50^{t h}$ & $75^{\text {th }}$ & $95^{\text {th }}$ \\
\hline \multicolumn{8}{|c|}{ Panel A: SPG Model $\left(R^{2}=.978\right)$} \\
\hline$\beta_{0}$ & 0.001 & 0.018 & -0.022 & -0.007 & 0.000 & 0.008 & 0.025 \\
\hline$\beta_{1}$ & 0.456 & 0.087 & 0.343 & 0.402 & 0.449 & 0.504 & 0.594 \\
\hline$\beta_{2}$ & 0.044 & 0.048 & -0.004 & 0.025 & 0.039 & 0.057 & 0.106 \\
\hline$\beta_{3}$ & 0.164 & 0.074 & 0.066 & 0.118 & 0.158 & 0.203 & 0.288 \\
\hline$\beta_{4}$ & 0.023 & 0.021 & -0.002 & 0.015 & 0.023 & 0.032 & 0.050 \\
\hline$\gamma_{1}$ & 0.059 & 0.043 & -0.003 & 0.039 & 0.060 & 0.080 & 0.114 \\
\hline$\gamma_{2}$ & 0.347 & 0.121 & 0.163 & 0.270 & 0.346 & 0.418 & 0.543 \\
\hline$\gamma_{3}$ & 0.124 & 0.062 & 0.041 & 0.085 & 0.118 & 0.155 & 0.225 \\
\hline$\gamma_{4}$ & 0.135 & 0.059 & 0.052 & 0.100 & 0.132 & 0.166 & 0.229 \\
\hline$\gamma_{5}$ & 0.047 & 0.040 & -0.006 & 0.029 & 0.046 & 0.064 & 0.102 \\
\hline$\varphi_{1}$ & 0.075 & 0.086 & -0.048 & 0.033 & 0.076 & 0.119 & 0.193 \\
\hline$\varphi_{2}$ & 0.202 & 0.256 & -0.106 & 0.077 & 0.174 & 0.296 & 0.615 \\
\hline$\varphi_{3}$ & 0.046 & 1.414 & -1.040 & -0.226 & 0.071 & 0.351 & 1.155 \\
\hline \multicolumn{8}{|c|}{ Panel B: PG Model $\left(R^{2}=.916\right)$} \\
\hline$\beta_{0}$ & -0.010 & 0.007 & -0.021 & -0.014 & -0.009 & -0.005 & 0.000 \\
\hline$\beta_{1}$ & 0.465 & 0.069 & 0.360 & 0.417 & 0.461 & 0.509 & 0.586 \\
\hline$\beta_{2}$ & 0.036 & 0.014 & 0.015 & 0.026 & 0.035 & 0.044 & 0.058 \\
\hline$\beta_{3}$ & 0.176 & 0.050 & 0.094 & 0.144 & 0.175 & 0.207 & 0.257 \\
\hline$\beta_{4}$ & 0.026 & 0.010 & 0.009 & 0.019 & 0.026 & 0.032 & 0.041 \\
\hline$\gamma_{1}$ & 0.053 & 0.015 & 0.027 & 0.045 & 0.054 & 0.063 & 0.076 \\
\hline$\gamma_{2}$ & 0.342 & 0.123 & 0.122 & 0.264 & 0.352 & 0.428 & 0.524 \\
\hline$\gamma_{3}$ & 0.130 & 0.046 & 0.052 & 0.101 & 0.131 & 0.160 & 0.202 \\
\hline$\gamma_{4}$ & 0.154 & 0.054 & 0.067 & 0.120 & 0.153 & 0.188 & 0.243 \\
\hline$\gamma_{5}$ & 0.044 & 0.011 & 0.026 & 0.037 & 0.044 & 0.051 & 0.061 \\
\hline$\varphi_{1}$ & 0.062 & 0.031 & 0.012 & 0.041 & 0.061 & 0.082 & 0.114 \\
\hline$\varphi_{2}$ & 0.143 & 0.126 & -0.041 & 0.054 & 0.131 & 0.218 & 0.371 \\
\hline$\varphi_{3}$ & 0.057 & 0.147 & -0.178 & -0.021 & 0.064 & 0.148 & 0.271 \\
\hline \multicolumn{8}{|c|}{ Panel C: PL Model $\left(R^{2}=.8474\right)$} \\
\hline$\beta_{0}$ & 0.000 & 0.005 & -0.007 & -0.003 & 0.000 & 0.004 & 0.009 \\
\hline$\beta_{1}$ & 0.392 & 0.094 & 0.251 & 0.325 & 0.384 & 0.450 & 0.561 \\
\hline$\beta_{2}$ & 0.021 & 0.040 & -0.050 & -0.003 & 0.023 & 0.046 & 0.082 \\
\hline$\beta_{3}$ & 0.312 & 0.091 & 0.163 & 0.256 & 0.313 & 0.368 & 0.460 \\
\hline$\beta_{4}$ & 0.024 & 0.020 & -0.010 & 0.012 & 0.025 & 0.038 & 0.056 \\
\hline$\gamma_{1}$ & 0.103 & 0.047 & 0.020 & 0.075 & 0.107 & 0.134 & 0.174 \\
\hline$\gamma_{2}$ & 0.471 & 0.153 & 0.211 & 0.375 & 0.476 & 0.574 & 0.712 \\
\hline$\gamma_{3}$ & 0.149 & 0.076 & 0.024 & 0.100 & 0.150 & 0.199 & 0.271 \\
\hline$\gamma_{4}$ & 0.228 & 0.106 & 0.058 & 0.162 & 0.227 & 0.296 & 0.401 \\
\hline$\gamma_{5}$ & 0.043 & 0.029 & -0.002 & 0.024 & 0.042 & 0.060 & 0.089 \\
\hline$\varphi_{1}$ & -0.040 & 0.035 & -0.101 & -0.061 & -0.038 & -0.017 & 0.012 \\
\hline$\varphi_{2}$ & 1.227 & 0.290 & 0.785 & 1.057 & 1.219 & 1.396 & 1.709 \\
\hline$\varphi_{3}$ & 1.430 & 0.666 & 0.400 & 1.005 & 1.445 & 1.910 & 2.415 \\
\hline
\end{tabular}

The data used for estimation include 60,868 year-bank observations for 7,473 different banks from 2001 to 2010 . SPG model, PG model, and PL model correspond to the estimation of the functional coefficients in equation (5) using the semiparametric smooth coefficient model (SPSCM), a parametric translog growth model, and the parametric translog model in levels, respectively. 
Table 3: Summary Statistics for Returns to Scale Estimates by Bank Size

\begin{tabular}{|c|c|c|c|c|c|c|c|}
\hline \multirow{2}{*}{ Bank size } & \multirow[b]{2}{*}{ Mean } & \multirow[b]{2}{*}{ sd } & \multicolumn{5}{|c|}{ Percentiles } \\
\hline & & & $5^{\text {th }}$ & $25^{\text {th }}$ & $50^{t h}$ & $75^{\text {th }}$ & $95^{\text {th }}$ \\
\hline \multicolumn{8}{|l|}{ Panel A: SPG Model } \\
\hline TOP100 & 1.127 & 0.276 & 0.799 & 0.959 & 1.086 & 1.237 & 1.577 \\
\hline Big & 1.180 & 0.234 & 0.903 & 1.044 & 1.144 & 1.266 & 1.581 \\
\hline Medium & 1.335 & 0.164 & 1.130 & 1.239 & 1.311 & 1.399 & 1.626 \\
\hline Small & 1.561 & 0.263 & 1.263 & 1.389 & 1.512 & 1.670 & 2.020 \\
\hline All & 1.425 & 0.247 & 1.135 & 1.274 & 1.375 & 1.532 & 1.860 \\
\hline \multicolumn{8}{|l|}{ Panel B: PG Model } \\
\hline TOP100 & 1.011 & 0.087 & 0.859 & 0.957 & 1.019 & 1.065 & 1.144 \\
\hline Big & 1.103 & 0.095 & 0.920 & 1.052 & 1.112 & 1.162 & 1.240 \\
\hline Medium & 1.323 & 0.098 & 1.177 & 1.255 & 1.317 & 1.381 & 1.491 \\
\hline Small & 1.541 & 0.141 & 1.356 & 1.436 & 1.516 & 1.621 & 1.810 \\
\hline All & 1.403 & 0.174 & 1.152 & 1.287 & 1.386 & 1.502 & 1.722 \\
\hline \multicolumn{8}{|l|}{ Panel C: PL Model } \\
\hline TOP100 & 1.036 & 0.050 & 0.964 & 1.002 & 1.031 & 1.064 & 1.132 \\
\hline Big & 1.022 & 0.043 & 0.963 & 0.993 & 1.016 & 1.043 & 1.100 \\
\hline Medium & 1.008 & 0.034 & 0.953 & 0.986 & 1.007 & 1.028 & 1.064 \\
\hline Small & 1.009 & 0.035 & 0.953 & 0.986 & 1.009 & 1.032 & 1.067 \\
\hline All & 1.009 & 0.035 & 0.954 & 0.987 & 1.008 & 1.031 & 1.067 \\
\hline \multicolumn{8}{|c|}{$\begin{array}{l}\text { This table shows summary statistic for RTS estimates. The data used for estimation include } 60,868 \\
\text { year-bank observations for } 7,473 \text { different banks from } 2001 \text { to } 2010 \text {. SPG model, PG model, and PL } \\
\text { model correspond to RTS estimates computed after estimating (5) using the semiparametric smooth } \\
\text { coefficient model (SPSCM), a parametric translog growth model, and the parametric translog model } \\
\text { in levels, respectively. TOP100 corresponds to RTS estimates for the } 100 \text { biggest banks. Banks size } \\
\text { categories are: Big (assets }>\$ 1 \text { billion), medium ( } \$ 100 \text { million }<\text { assets }<\$ 1 \text { billion), and small (assets } \\
<\$ 100 \text { million) banks. }\end{array}$} \\
\hline
\end{tabular}


Table 4: Percentage of Big Banks with IRTS, DRTS, or CRTS.

\begin{tabular}{|c|c|c|c|c|c|c|c|c|c|c|}
\hline \multicolumn{11}{|c|}{ Medium and Small Banks } \\
\hline & & \multicolumn{3}{|c|}{ SPG Model } & \multicolumn{3}{|c|}{ PG Model } & \multicolumn{3}{|c|}{ PL Model } \\
\hline Year & $\mathbf{N}$ & IRTS & DRTS & CRTS & IRTS & DRTS & CRTS & IRTS & DRTS & CRTS \\
\hline 2002 & 5021 & $95 \%$ & $0 \%$ & $4 \%$ & $100 \%$ & $0 \%$ & $0 \%$ & $14 \%$ & $32 \%$ & $54 \%$ \\
\hline 2003 & 6181 & $99 \%$ & $0 \%$ & $1 \%$ & $100 \%$ & $0 \%$ & $0 \%$ & $29 \%$ & $19 \%$ & $52 \%$ \\
\hline 2004 & 6175 & $99 \%$ & $0 \%$ & $1 \%$ & $100 \%$ & $0 \%$ & $0 \%$ & $35 \%$ & $15 \%$ & $50 \%$ \\
\hline 2005 & 6066 & $99 \%$ & $0 \%$ & $1 \%$ & $100 \%$ & $0 \%$ & $0 \%$ & $28 \%$ & $21 \%$ & $51 \%$ \\
\hline 2006 & 5852 & $98 \%$ & $0 \%$ & $1 \%$ & $100 \%$ & $0 \%$ & $0 \%$ & $19 \%$ & $30 \%$ & $51 \%$ \\
\hline 2007 & 5554 & $99 \%$ & $0 \%$ & $1 \%$ & $100 \%$ & $0 \%$ & $0 \%$ & $15 \%$ & $35 \%$ & $50 \%$ \\
\hline 2008 & 5161 & $99 \%$ & $0 \%$ & $1 \%$ & $100 \%$ & $0 \%$ & $0 \%$ & $29 \%$ & $20 \%$ & $51 \%$ \\
\hline 2009 & 4718 & $99 \%$ & $0 \%$ & $1 \%$ & $100 \%$ & $0 \%$ & $0 \%$ & $48 \%$ & $7 \%$ & $45 \%$ \\
\hline 2010 & 4364 & $98 \%$ & $0 \%$ & $2 \%$ & $100 \%$ & $0 \%$ & $0 \%$ & $65 \%$ & $3 \%$ & $33 \%$ \\
\hline Avg & 5455 & $98 \%$ & $0 \%$ & $2 \%$ & $100 \%$ & 0\% & $0 \%$ & $31 \%$ & $20 \%$ & $49 \%$ \\
\hline
\end{tabular}

Big Banks

\begin{tabular}{|c|c|c|c|c|c|c|c|c|c|c|}
\hline \multirow[b]{2}{*}{ Year } & \multirow[b]{2}{*}{$\mathbf{N}$} & \multicolumn{3}{|c|}{ SPG Model } & \multicolumn{3}{|c|}{ PG Model } & \multicolumn{3}{|c|}{ PL Model } \\
\hline & & IRTS & DRTS & CRTS & IRTS & DRTS & CRTS & IRTS & DRTS & CRTS \\
\hline 2002 & 260 & $68 \%$ & $23 \%$ & $8 \%$ & $70 \%$ & $6 \%$ & $24 \%$ & $23 \%$ & $9 \%$ & $68 \%$ \\
\hline 2003 & 309 & $83 \%$ & $12 \%$ & $5 \%$ & $75 \%$ & $5 \%$ & $20 \%$ & $41 \%$ & $5 \%$ & $54 \%$ \\
\hline 2004 & 340 & $85 \%$ & $7 \%$ & $8 \%$ & $76 \%$ & $5 \%$ & $19 \%$ & $39 \%$ & $8 \%$ & $54 \%$ \\
\hline 2005 & 355 & $70 \%$ & $12 \%$ & $18 \%$ & $73 \%$ & $6 \%$ & $21 \%$ & $27 \%$ & $17 \%$ & $55 \%$ \\
\hline 2006 & 364 & $59 \%$ & $18 \%$ & $23 \%$ & $69 \%$ & $7 \%$ & $24 \%$ & $14 \%$ & $31 \%$ & $55 \%$ \\
\hline 2007 & 349 & $65 \%$ & $13 \%$ & $22 \%$ & $68 \%$ & $6 \%$ & $26 \%$ & $10 \%$ & $39 \%$ & $51 \%$ \\
\hline 2008 & 323 & $80 \%$ & $11 \%$ & $9 \%$ & $72 \%$ & $7 \%$ & $21 \%$ & $24 \%$ & $21 \%$ & $54 \%$ \\
\hline 2009 & 306 & $79 \%$ & $10 \%$ & $10 \%$ & $76 \%$ & $5 \%$ & $19 \%$ & $49 \%$ & $8 \%$ & $43 \%$ \\
\hline 2010 & 268 & $72 \%$ & $14 \%$ & $14 \%$ & $82 \%$ & $3 \%$ & $15 \%$ & $65 \%$ & $3 \%$ & $32 \%$ \\
\hline Avg & 319 & $73 \%$ & $13 \%$ & $13 \%$ & $74 \%$ & $5 \%$ & $21 \%$ & $32 \%$ & $16 \%$ & $52 \%$ \\
\hline
\end{tabular}

Top 100 Banks

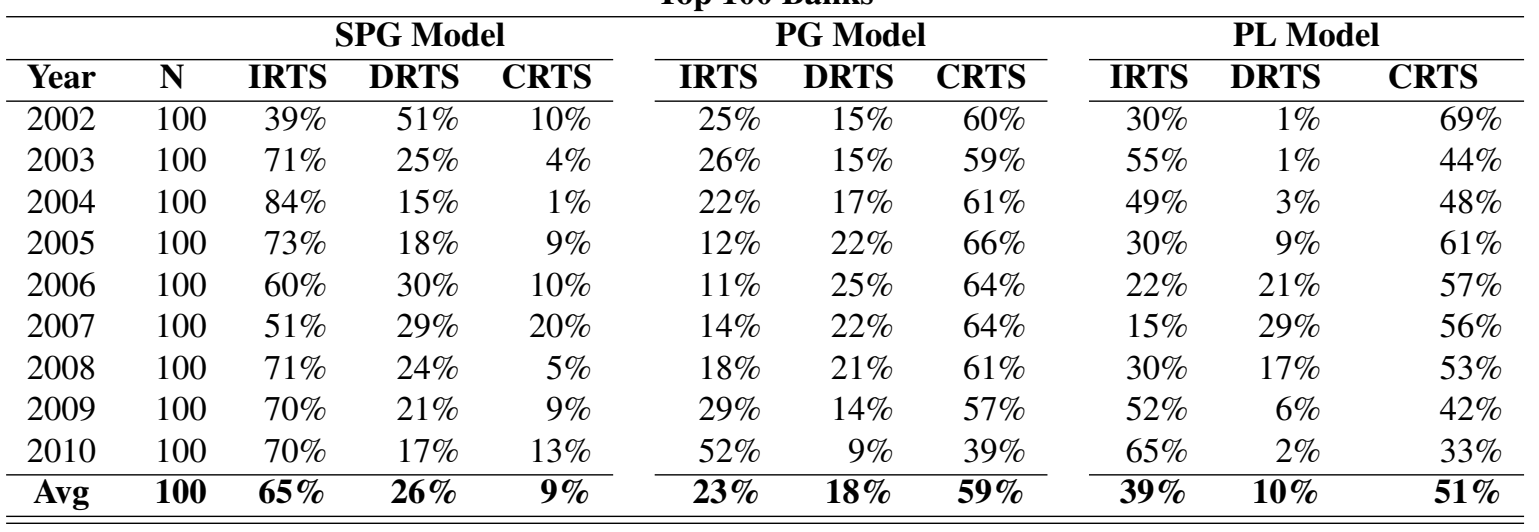

This table shows the percentage of observations with statistically significant increasing (IRTS), decreasing (DRTS), and constant (CRTS) RTS. A specific RTS estimate indicates IRTS, DRTS, or CRTS if its $95 \%$ confidence interval lies entirely above, entirely below, or includes one, respectively. The data used for estimation include 60,868 year-bank observations for 7,473 different banks from 2001 to 2010. SPG model, PG model, and PL model correspond to RTS estimates computed after estimating (5) using the semiparametric smooth coefficient model (SPSCM), a parametric translog growth model, and the parametric translog model in levels, respectively. TOP100 corresponds to RTS estimates for the 100 biggest banks. Banks size categories are: Big (assets $>\$ 1$ billion), medium ( $\$ 100$ million $<$ assets $<\$ 1$ billion), and small (assets $<\$ 100$ million) banks. 
Table 5: TFP Components

\begin{tabular}{|c|c|c|c|c|c|c|c|}
\hline \multirow[b]{2}{*}{ Variable } & \multirow[b]{2}{*}{ Mean } & \multirow[b]{2}{*}{ sd } & \multicolumn{5}{|c|}{ Percentiles } \\
\hline & & & $5^{\text {th }}$ & $25^{\text {th }}$ & $50^{\text {th }}$ & $75^{\text {th }}$ & $95^{\text {th }}$ \\
\hline TFP Divisia & 0.031 & 0.083 & -0.077 & -0.009 & 0.026 & 0.064 & 0.150 \\
\hline Panel A: SPG Model & & & & & & & \\
\hline TFP Growth & 0.031 & 0.076 & -0.057 & -0.005 & 0.024 & 0.058 & 0.140 \\
\hline Scale & 0.022 & 0.070 & -0.053 & -0.009 & 0.013 & 0.041 & 0.120 \\
\hline TC & -0.001 & 0.018 & -0.025 & -0.008 & 0.000 & 0.007 & 0.022 \\
\hline Allocative & 0.017 & 0.042 & -0.040 & -0.005 & 0.013 & 0.037 & 0.087 \\
\hline Exogenous & -0.007 & 0.025 & -0.036 & -0.011 & -0.004 & 0.000 & 0.014 \\
\hline Panel B: PG Model & & & & & & & \\
\hline TFP Growth & 0.031 & 0.071 & -0.058 & -0.005 & 0.024 & 0.059 & 0.139 \\
\hline Scale & 0.018 & 0.063 & -0.052 & -0.009 & 0.012 & 0.037 & 0.108 \\
\hline $\mathrm{TC}$ & 0.010 & 0.007 & 0.000 & 0.005 & 0.009 & 0.014 & 0.021 \\
\hline Allocative & 0.007 & 0.038 & -0.049 & -0.013 & 0.006 & 0.026 & 0.068 \\
\hline Exogenous & -0.004 & 0.012 & -0.020 & -0.007 & -0.003 & -0.000 & 0.007 \\
\hline Panel C: PL Model & & & & & & & \\
\hline TFP Growth & 0.011 & 0.084 & -0.106 & -0.030 & 0.008 & 0.050 & 0.135 \\
\hline Scale & 0.002 & 0.051 & -0.066 & -0.017 & 0.003 & 0.022 & 0.065 \\
\hline TC & -0.000 & 0.005 & -0.009 & -0.004 & -0.000 & 0.003 & 0.007 \\
\hline Allocative & 0.008 & 0.057 & -0.081 & -0.021 & 0.008 & 0.038 & 0.097 \\
\hline Exogenous & 0.002 & 0.043 & -0.046 & -0.013 & -0.000 & 0.012 & 0.052 \\
\hline
\end{tabular}


Table 6: TFP Components Variance Contribution

\begin{tabular}{|c|c|c|c|c|c|c|}
\hline TFP Component & $\begin{array}{l}\text { Semipartial } \\
\text { correlation }\end{array}$ & $\begin{array}{l}\text { Common } \\
\text { variance }\end{array}$ & $\begin{array}{l}\text { Bootstrap } \\
\text { Std. Errors }\end{array}$ & P-value & {$[95 \%$ Conf. } & Interval] \\
\hline \multicolumn{7}{|l|}{ Panel A: SPG Model } \\
\hline Technical Change & 0.218 & 0.048 & 0.006 & 0.000 & 0.036 & 0.059 \\
\hline Allocative & 0.524 & 0.275 & 0.007 & 0.000 & 0.261 & 0.289 \\
\hline Scale & 0.895 & 0.801 & 0.006 & 0.000 & 0.789 & 0.812 \\
\hline Exogeneous & 0.326 & 0.106 & 0.010 & 0.000 & 0.087 & 0.126 \\
\hline \multicolumn{7}{|l|}{ Panel B: PG Model } \\
\hline Technical Change & 0.090 & 0.008 & 0.001 & 0.000 & 0.006 & 0.010 \\
\hline Allocative & 0.527 & 0.278 & 0.008 & 0.000 & 0.262 & 0.294 \\
\hline Scale & 0.864 & 0.746 & 0.008 & 0.000 & 0.731 & 0.761 \\
\hline Exogeneous & 0.165 & 0.027 & 0.005 & 0.000 & 0.018 & 0.037 \\
\hline \multicolumn{7}{|l|}{ Panel C: PL Model } \\
\hline Technical Change & 0.060 & 0.004 & 0.001 & 0.000 & 0.002 & 0.005 \\
\hline Allocative & 0.668 & 0.446 & 0.013 & 0.000 & 0.421 & 0.471 \\
\hline Scale & 0.610 & 0.372 & 0.015 & 0.000 & 0.343 & 0.401 \\
\hline Exogeneous & 0.505 & 0.255 & 0.015 & 0.000 & 0.227 & 0.284 \\
\hline
\end{tabular}



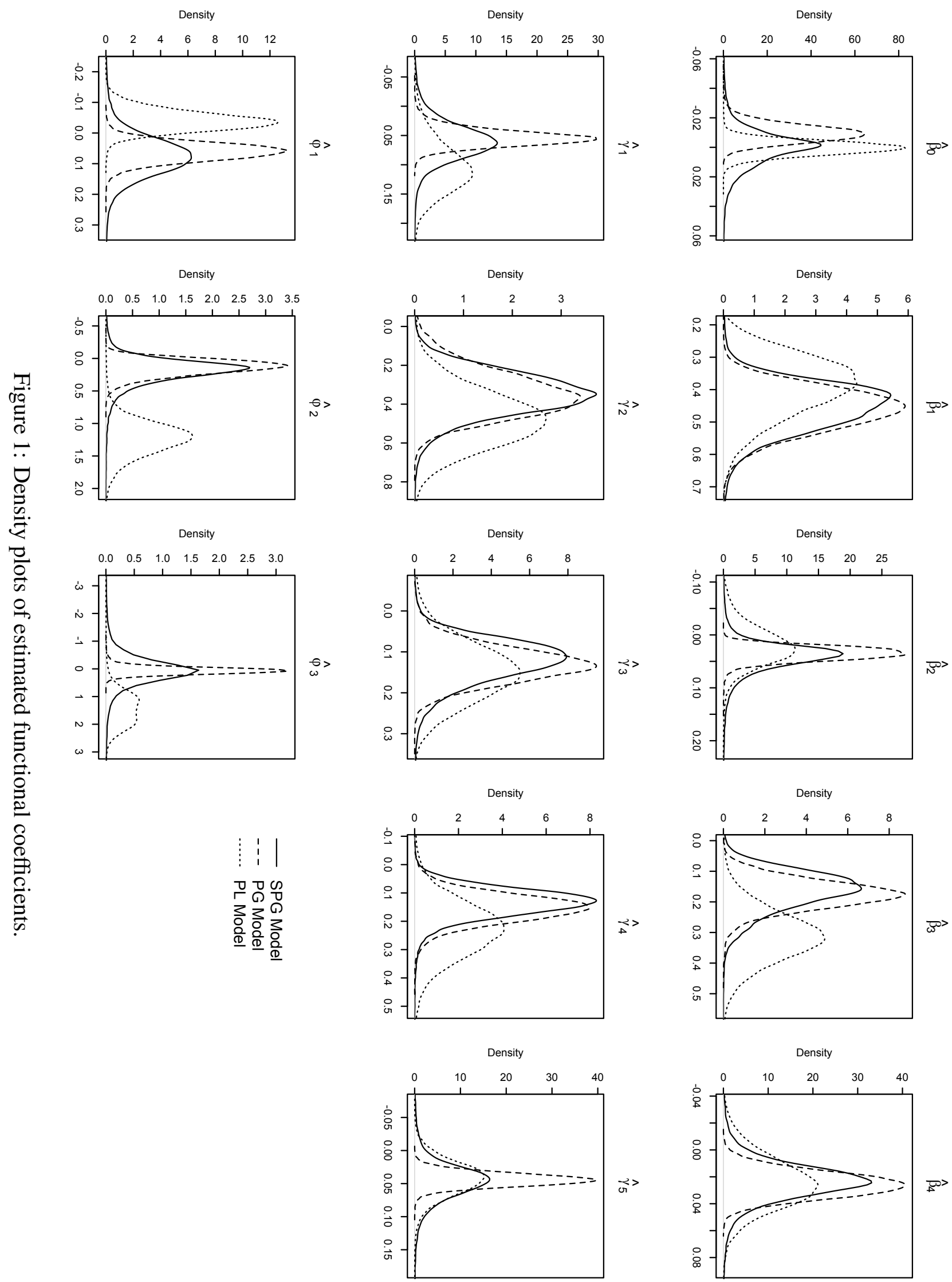

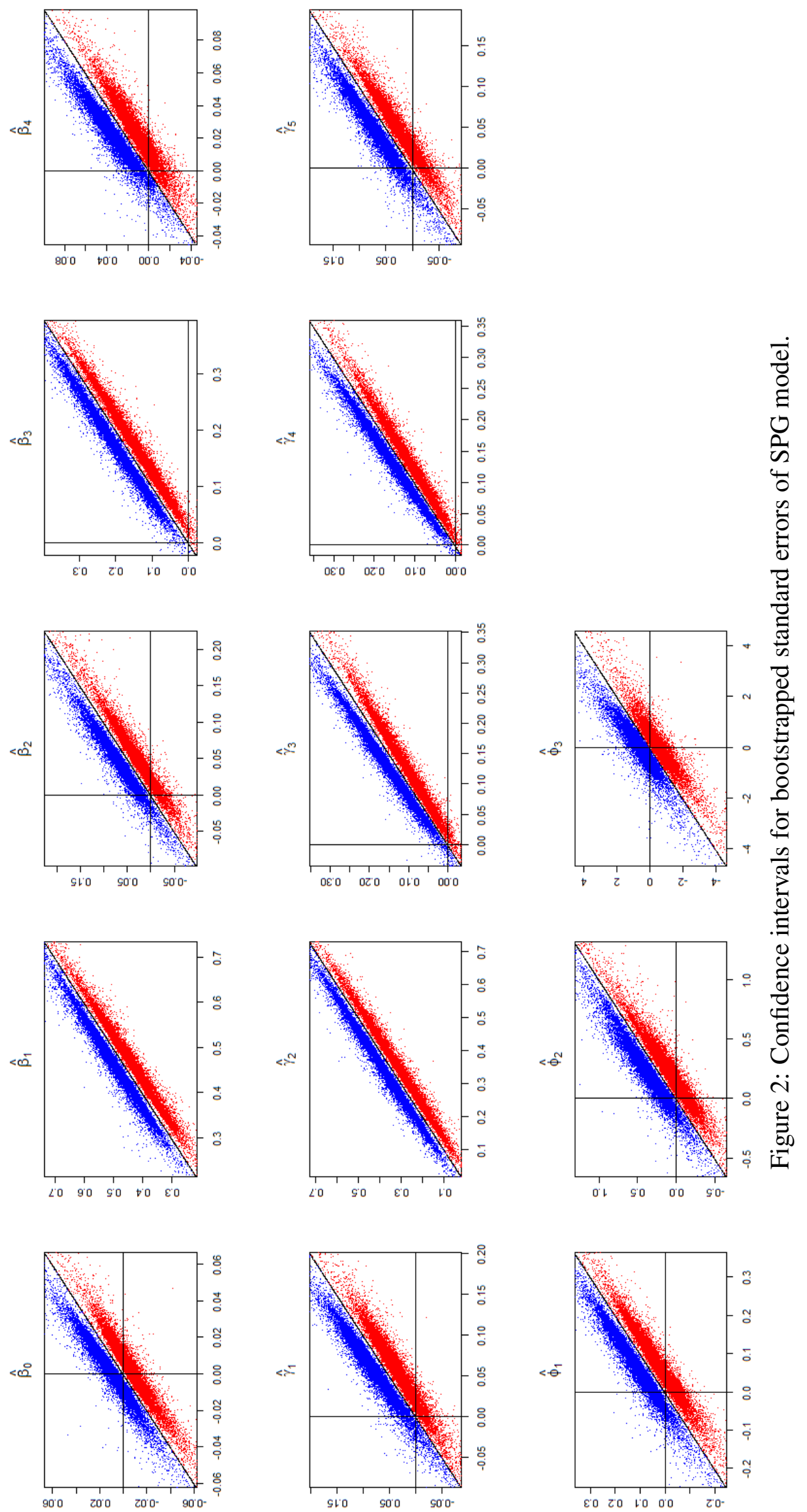


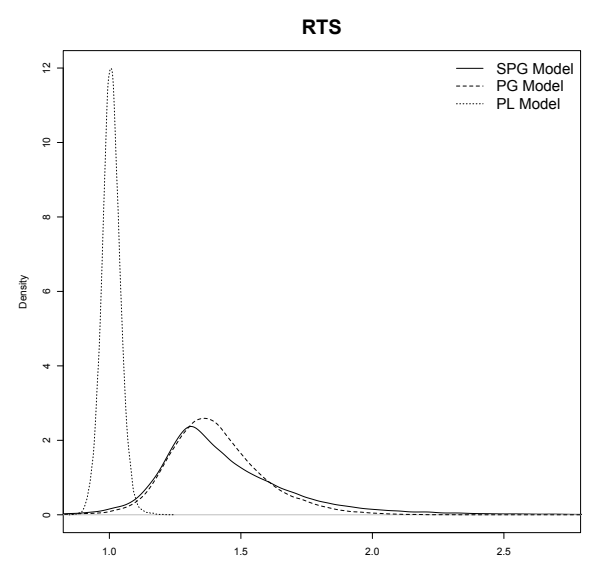

Figure 3: Density plots for RTS estimates for all banks.
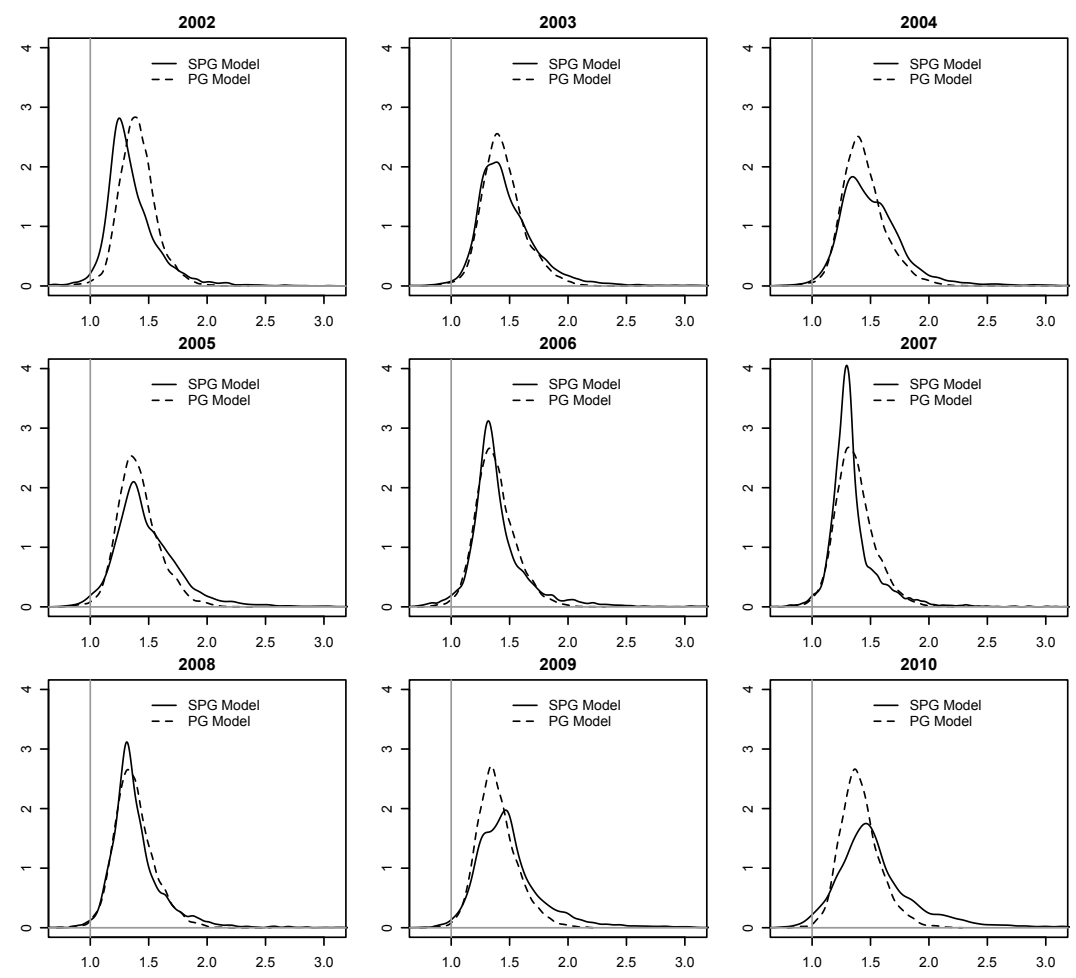

Figure 4: RTS estimates over time. 

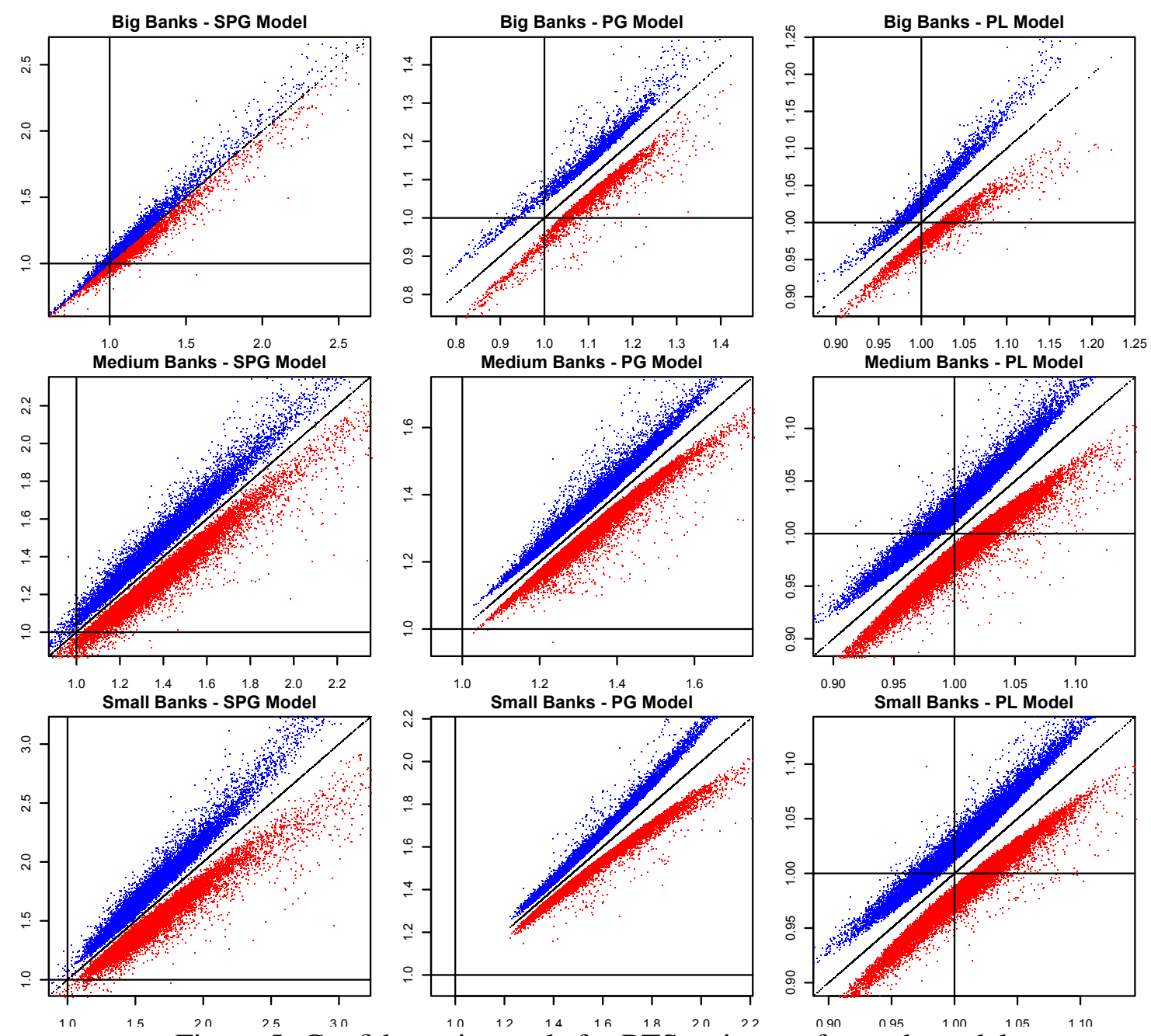

Figure 5: Confidence intervals for RTS estimates for each model 

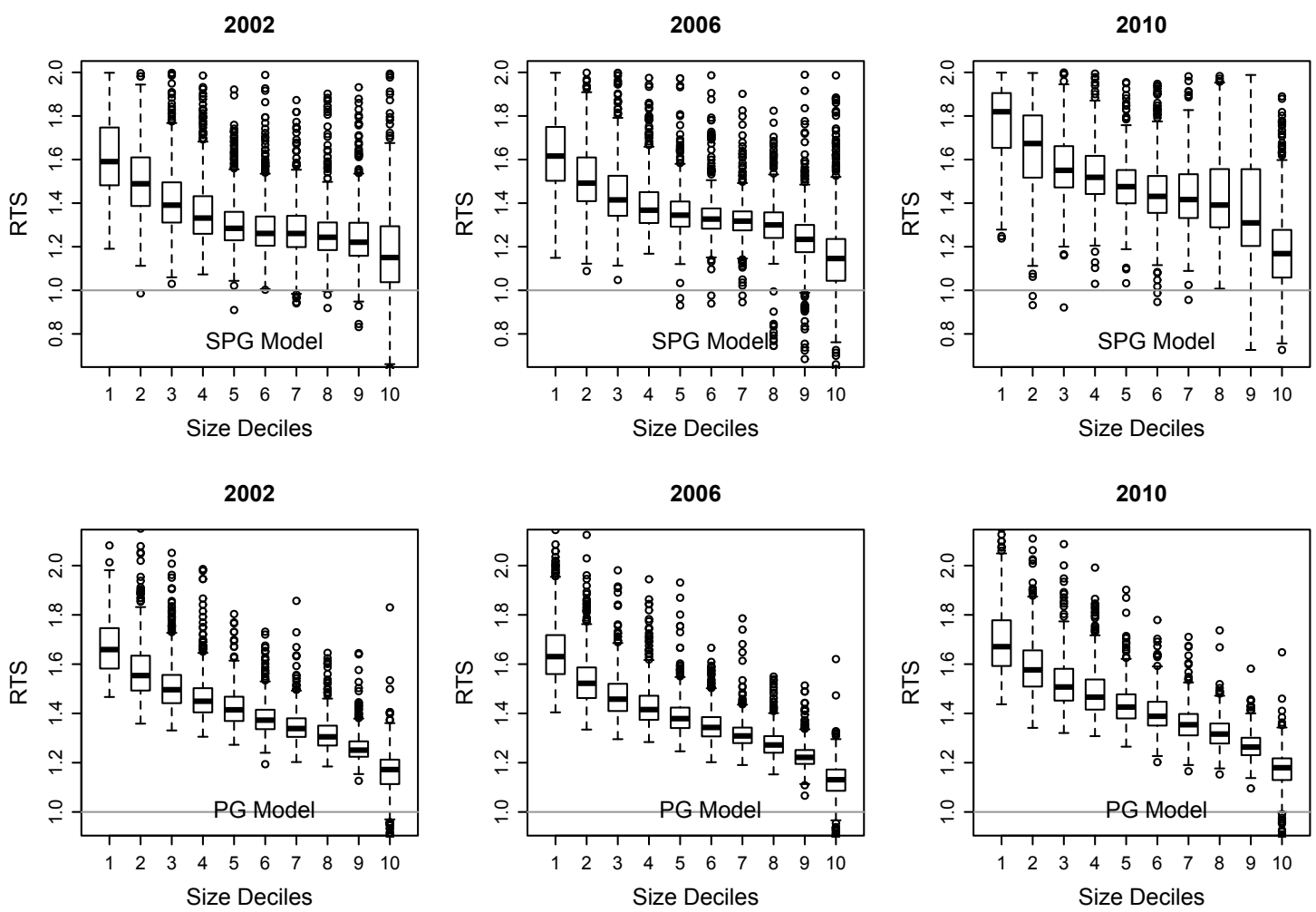

Figure 6: RTS estimates from SPG and PG models by bank size deciles based on total assets.
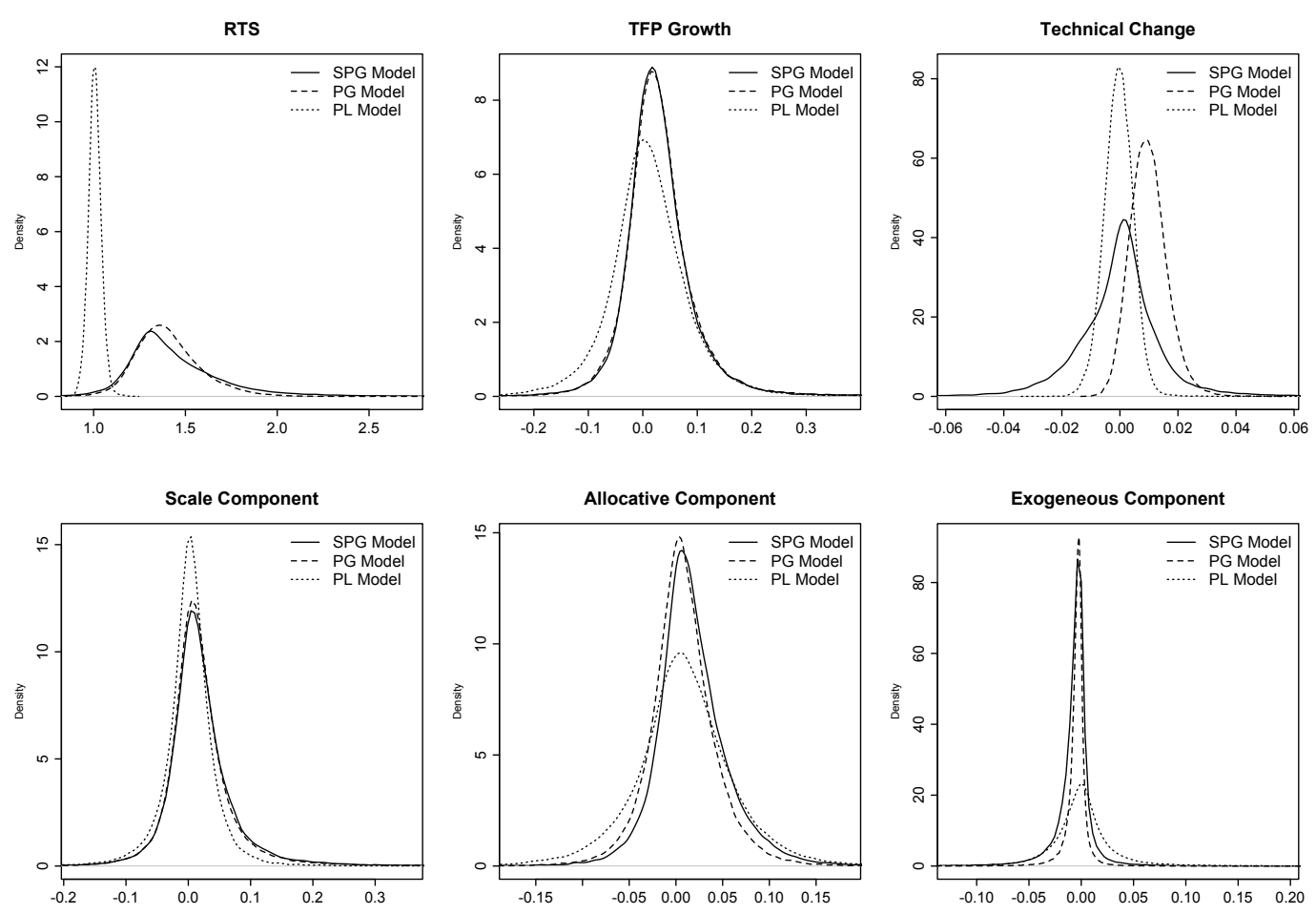

Figure 7: Density plots for RTS and TFP components. 

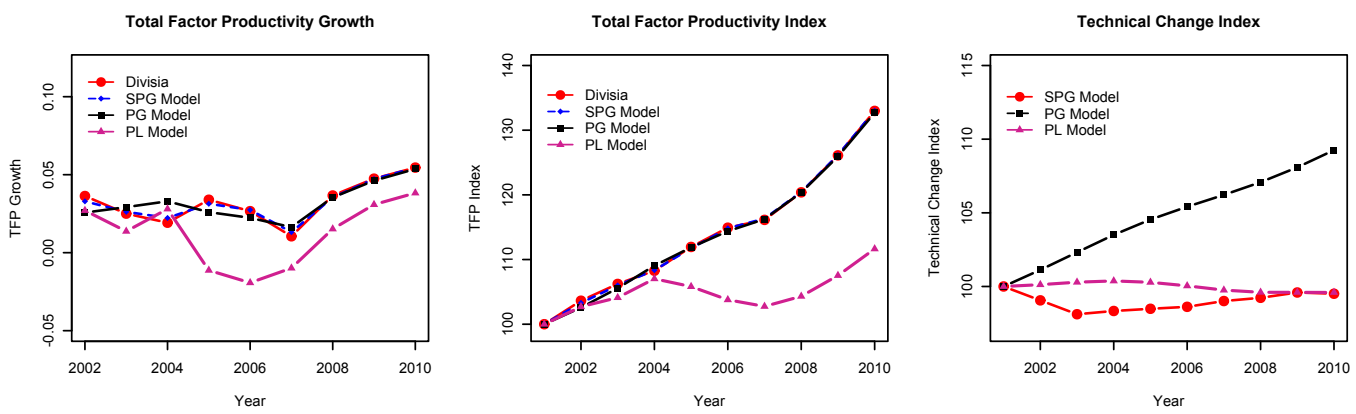

Scale Index
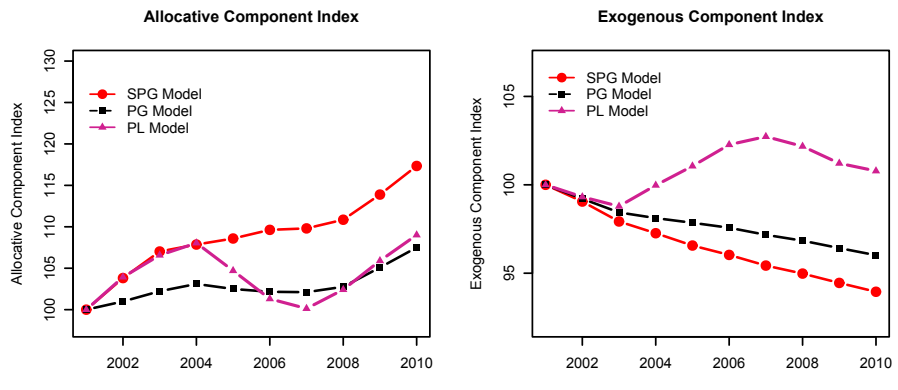

Figure 8: TFP Growth and TFP Indexes over time. 


\section{Appendix A. Translog Specifications}

Assuming that $f(\cdot)$ in (3) is translog, the estimating equation for the PL model is:

$$
\begin{aligned}
f(\cdot)= & \alpha_{0}+\sum_{k=1}^{K-1} \theta_{k} \ln \widetilde{W}_{k}+\frac{1}{2} \sum_{k=1}^{K-1} \sum_{m=1}^{K-1} \theta_{k m} \ln \widetilde{W}_{k} \ln \widetilde{W}_{m}+\sum_{q=1}^{Q} \alpha_{q} \ln Y_{q}+\frac{1}{2} \sum_{q=1}^{Q} \sum_{o=1}^{Q} \alpha_{q o} \ln Y_{q} \ln Y_{o} \\
& +\sum_{q=1}^{Q} \sum_{k=1}^{K-1} \delta_{q k} \ln Y_{q} \ln \widetilde{W}_{k}+\alpha_{t} t+\frac{1}{2} \alpha_{t t} t^{2}+\sum_{q=1}^{Q} \lambda_{q t} \ln Y_{q} t+\sum_{k=1}^{K-1} \delta_{k t} \ln \widetilde{W}_{k} t+\sum_{p=1}^{P} \phi_{p} Z_{p} \\
& +\frac{1}{2} \sum_{p=1}^{P} \sum_{l=1}^{P} \phi_{p l} Z_{p} Z_{l}+\sum_{p=1}^{P} \sum_{k=1}^{K-1} \rho_{p k} Z_{p} \ln \widetilde{W}_{k}+\sum_{p=1}^{P} \sum_{q=1}^{Q} \tau_{p q} Z_{p} \ln Y_{q}+\sum_{p=1}^{P} \phi_{p t} Z_{p} t+u
\end{aligned}
$$

After estimating (A.1), the functional coefficients for the PL model are computed using:

$$
\begin{aligned}
\frac{\partial f}{\partial \ln \widetilde{W}_{k}} & =\beta_{k}(\cdot)=\theta_{k}+\sum_{m=1}^{K-1} \theta_{k m} \ln \widetilde{W}_{m}+\sum_{q=1}^{Q} \delta_{q k} \ln Y_{q}+\delta_{k t} t+\sum_{p=1}^{P} \rho_{p k} Z_{p}, \forall k=1, \ldots, K-1 \\
\frac{\partial f}{\partial \ln Y_{q}} & =\gamma_{q}(\cdot)=\alpha_{q}+\sum_{o=1}^{Q} \alpha_{q o} \ln Y_{o}+\sum_{k=1}^{K-1} \delta_{q k} \ln \widetilde{W}_{k}+\lambda_{q t} t+\sum_{p=1}^{P} \tau_{p q} Z_{p}, \forall q=1, \ldots, Q \\
\frac{\partial f}{\partial Z_{p}} & =\varphi_{p}(\cdot)=\phi_{p}+\sum_{l=1}^{P} \phi_{p l} Z_{l}+\sum_{k=1}^{K-1} \rho_{p k} \ln \widetilde{W}_{k}+\sum_{q=1}^{Q} \tau_{p q} \ln Y_{q}+\phi_{p t} t, \forall p=1, \ldots, P \\
\frac{\partial f}{\partial t} & =\beta_{0}(\cdot)=\alpha_{t}+\alpha_{t t} t+\sum_{q=1}^{Q} \lambda_{q t} \ln Y_{q}+\sum_{k=1}^{K-1} \delta_{k t} \ln \widetilde{W}_{k}+\sum_{p=1}^{P} \phi_{p t} Z_{p}
\end{aligned}
$$

Plugging (A.2)-(A.5) into (5) gives:

$$
\begin{aligned}
\dot{\widetilde{C}}= & {\left[\alpha_{t}+\alpha_{t t} t+\sum_{q=1}^{Q} \lambda_{q t} \ln Y_{q}+\sum_{k=1}^{K-1} \delta_{k t} \ln \widetilde{W}_{k}+\sum_{p=1}^{P} \phi_{p t} Z_{p}\right] } \\
& +\sum_{k=1}^{K-1}\left[\theta_{k}+\sum_{m=1}^{K-1} \theta_{k m} \ln \widetilde{W}_{m}+\sum_{q=1}^{Q} \delta_{q k} \ln Y_{q}+\delta_{k t} t+\sum_{p=1}^{P} \rho_{p k} Z_{p}\right] \dot{\vec{W}}_{k} \\
& +\sum_{q=1}^{Q}\left[\alpha_{q}+\sum_{o=1}^{Q} \alpha_{q o} \ln Y_{o}+\sum_{k=1}^{K-1} \delta_{q k} \ln \widetilde{W}_{k}+\lambda_{q t} t+\sum_{p=1}^{P} \tau_{p q} Z_{p}\right] \dot{Y}_{q} \\
& +\sum_{p=1}^{P}\left[\phi_{p}+\sum_{l=1}^{P} \phi_{p l} Z_{l}+\sum_{k=1}^{K-1} \rho_{p k} \ln \widetilde{W}_{k}+\sum_{q=1}^{Q} \tau_{p q} \ln Y_{q}+\phi_{p t} t\right] \nabla_{t} Z_{p}+u
\end{aligned}
$$


Rearranging (A.6) gives the estimating equation for the PG model as follows:

$$
\begin{aligned}
\dot{\widetilde{C}}= & \alpha_{t}+\alpha_{t t} t+\sum_{k=1}^{K-1} \theta_{k} \dot{\tilde{W}}_{k}+\sum_{k=1}^{K-1} \sum_{m=1}^{K-1} \theta_{k m} \ln \widetilde{W}_{m} \dot{\tilde{W}}_{k}+\sum_{q=1}^{Q} \alpha_{q} \dot{Y}_{q}+\sum_{q=1}^{Q} \sum_{o=1}^{Q} \alpha_{q o} \ln Y_{o} \dot{Y}_{q} \\
& +\sum_{p=1}^{P} \phi_{p} \nabla_{t} Z_{p}+\sum_{p=1}^{P} \sum_{l=1}^{P} \phi_{p l} Z_{l} \nabla_{t} Z_{p}+\sum_{q=1}^{Q} \lambda_{q t}\left(\ln Y_{q}+t \dot{Y}_{q}\right)+\sum_{k=1}^{K-1} \delta_{k t}\left(\ln \widetilde{W}_{k}+t \dot{\tilde{W}}_{k}\right) \\
& +\sum_{p=1}^{P} \phi_{p t}\left(Z_{p}+t \nabla_{t} Z_{p}\right)+\sum_{k=1}^{K-1} \sum_{q=1}^{Q} \delta_{q k}\left(\ln Y_{q} \dot{\tilde{W}}_{k}+\ln \widetilde{W}_{k} \dot{Y}_{q}\right) \\
& +\sum_{k=1}^{K-1} \sum_{p=1}^{P} \rho_{p k}\left(Z_{p} \dot{\tilde{W}}_{k}+\ln \widetilde{W}_{k} \nabla_{t} Z_{p}\right)+\sum_{q=1}^{Q} \sum_{p=1}^{P} \tau_{p q}\left(Z_{p} \dot{Y}_{q}+\ln Y_{q} \nabla_{t} Z_{p}\right)+u
\end{aligned}
$$

After estimating (A.7), we compute the functional coefficients for the PG model using (A.2)-(A.5). 